\title{
Pipeline Risk in Leveraged Loan Syndication*
}

\author{
Max Bruche ${ }^{\dagger}$ \\ Humboldt University of Berlin \\ Frederic Malherbe \\ University College London and CEPR \\ Ralf R. Meisenzahl ${ }^{\S}$ \\ Federal Reserve Bank of Chicago
}

November 26, 2019

\begin{abstract}
What is the economic role played by arrangers of leveraged loans, and what are the risks they face? We provide evidence that arrangers solve a demand discovery problem. Investors have incentives to feign little interest in the loan to obtain better terms. To deter such behavior, arrangers underprice hot deals and ration investors on cold deals. The risk associated with demand discovery is often shared between borrowers and arrangers. One implication is that to ration investors on cold deals, arrangers retain larger loan shares. This motive for retention is different from the monitoring incentive motive previously considered in the literature. (JEL G23, G24, G30)
\end{abstract}

${ }^{*}$ We thank Bo Becker, Tobias Berg, Jennifer Dlugosz, Amar Gande, Matthew Gustafson, Björn Imbierowicz, Rustom Irani, Victoria Ivashina, Sonia Falconieri, Alexander Ljungqvist, Farzad Saidi, Anthony Saunders, Sascha Steffen, Neeltje van Horen, and Edison Yu and participants at the various seminars and conferences at which this paper was presented. We thank S\&P Capital IQ LCD for giving us access to the LCD pipeline data and Angelica Aldana, Nicole Corazza, and Kerry Kantin for help with the data. We also thank KC Brechnitz, Scott Cham, Michael Josenhans, and Reza Zargham and many others, for enlightening conversations about the institutional setup and functioning of syndicated lending. Max Bruche gratefully acknowledges financial support from the European Commission under FP7 Marie Curie Career Integration [Grant 334382]. Part of this research was completed while Ralf Meisenzahl was a visitor at the London School of Economics' Center for Economic Performance. The views expressed in this paper are those of the authors and do not necessarily reflect the position of the Federal Reserve System. Send correspondence to Max Bruche, School of Business and Economics, Humboldt University of Berlin, Dorotheenstr. 1, 10099 Berlin, Germany; telephone: +49 (30) 2093-99472. E-mail: max.bruche@hu-berlin.de.

$\dagger$ Email: max. bruche@hu-berlin.de

${ }^{\ddagger}$ Email: f.malherbe@ucl.ac.uk

$\S$ Email: ralf.meisenzahl@chi.frb.org

(C) The Author 2020. Published by Oxford University Press on behalf of The Society for Financial Studies. This is an Open Access article distributed under the terms of the Creative Commons Attribution Non-Commercial License (http://creativecommons.org/licenses/by-nc/4.0/), which permits non-commercial re-use, distribution, and reproduction in any medium, provided the original work is properly cited. For commercial re-use, please contact journals.permissions@ oup.com 
We are investment bankers, not commercial bankers, which means that we underwrite to distribute, not to put a loan on our balance sheet.

—Matt Harris, Managing Director, Chase Securities, as quoted by Esty (2003)

\section{Introduction}

The market for leveraged loans, which are non-investment-grade syndicated loans to corporations, has grown rapidly in recent years. By some measures, it has overtaken the non-investment-grade bond market as a source of finance. Leveraged loans are typically arranged by banks, which sell the bulk of these loans to institutional investors. What is the economic function of the arranging banks in this market? What type of risk do they face?

To shed light on these questions, we examine the loan arranging process. We argue that to place the loan on the best possible terms, arrangers need to ascertain investors' willingness to pay. That is, they solve a demand discovery problem. Arrangers often bear part of the risk associated with demand uncertainty. When a loan is hot (i.e., demand is high), arrangers make money and place the loan in full. However, when the loan is cold, arrangers have to retain shares in the loan and may lose money. We refer to the risk that arrangers assume as "pipeline risk," because it is the risk associated with the loans in their syndication pipeline. The retention we describe reflects an incentive problem: investors must be rationed on cold loans to deter their incentives to "low ball." It sharply contrasts with the retention often emphasized in the literature on syndicated loans, namely, retention that commits to monitoring (Sufi, 2007).

Before turning to the empirics, we use a simple model to clarify the nature of pipeline risk and, in particular, the connection between retention and the need to ration investors. This model is a variant of standard models in the literature that describe demand discovery (Benveniste and Spindt, 1989). In these models, the seller need to ascertain how much investors are willing to 
pay for a security that is being issued. Investors have incentives to bid low. To obtain the best possible terms, the seller must deter such strategic behavior. To do so, the seller underprices hot issues - those for which investor express much interest, and they ration the quantities that investors receive on cold issues - those for which investors express little interest. In our variant, arrangers sell on behalf of borrowers and may underwrite a loan. When an arranger underwrites, it makes a promise to the borrower about not only the terms but also the amount that will be raised. When the loan is cold, the arranger is then on the hook and will optimally choose to retain shares in the loan so as to be able to ration.

To test the model's predictions, we use the S\&P Capital IQ's Leveraged Commentary and Data (LCD). Our version of LCD contains information on leveraged loan syndication from 1999 to 2015, including information on the primary market price and the first secondary market price and on adjustments to loan terms, collectively referred to as "flex." With these data, we can compute underpricing by comparing primary to secondary market prices and can identify cold (hot) loans as those for which loan terms were flexed during syndication to make the loan more attractive to investors (to the borrower). We combine these data with data on arranger shares from the Shared National Credit Program (SNC), a register of syndicated loans compiled by U.S. financial regulators.

We find support for our predictions. First, hot loans are more underpriced: when interest rates are decreased by 100 bps, reflecting a hot loan, underpricing increases by about 7 bps. Second, when interest rates are flexed up, reflecting a cold loan, on average, the share retained by the arranger is larger, and amounts that the borrower receives are decreased. The point estimates imply that a 100-bps upward flex in spread is associated with an increase in the arranger share of around $2 \%$ to $6 \%$. This is substantial, given a median arranger share of about $2.6 \%$ in our data. Together, these results constitute the main contribution of the paper. They are strong evidence that (a) demand 
discovery is a key economic function of arrangers of leveraged loans and (b) arrangers retain a larger fraction of the cold, less desirable loans.

A natural follow-up question is whether there are consequences to pipeline risk. A typical worry for regulators is that adverse shocks to banks make them contract credit supply going forward. ${ }^{1}$ In our sample, we find that a 1-standard-deviation increase in the overall "coldness" of the loans arranged by a bank in a quarter is associated with a reduction in its participation in unrelated, new credit line syndications in the following quarter by about $4 \%-8 \% .^{2}$ The leveraged loan arranging activity of the bank also decreases by $12 \%-13 \%$. We will discuss other interpretations of this result in detail later. However, one possible interpretation, in line with regulators' macroprudential concerns, is that of a "cold-deal channel": arrangers retain more of the cold loans on their balance sheets and may incur losses. So cold deals tie up or erode bank capital and impair a bank's ability and willingness to support future activity. ${ }^{3}$

This argument would suggest that regulators may want to consider systematically collecting information on the confidential underwriting agreements that specify to what extent arrangers actually assume pipeline risk. Doing so would be very useful for quantifying pipeline risk ex ante. Constructing a pipeline risk indicator on the basis of such information would (a) allow regulators to actively monitor pipeline risk at the bank and the aggregate level; (b) inform the severity chosen for stress test scenarios; and (c) be a relevant input to specific capital charges that could (and probably should) apply to loans in the pipelines of banks.

\footnotetext{
${ }^{1}$ Pipeline risk is now included in some regulatory stress test exercises. For instance, according to the Bank of England's current governor, Mark Carney, the bank imposed, on average, a $22 \%$ loss rate on leveraged loans in banks' syndication pipelines in its latest stress test exercise, as indicated in testimony before the UK Treasury Committee on January 16, 2019. See https://parliamentlive.tv/event/index/ d8ed4184-ce36-477a-bd27-59c11f01c6e5.

${ }^{2}$ We focus on credit lines arranged by other banks to partially alleviate endogeneity concerns.

${ }^{3}$ Cold loan retention may also result in a form of debt overhang problem (Myers, 1977): the presence of risky assets on a firm's balance sheet decreases the firm's willingness to invest, because part of the surplus generated is captured by creditors. (See also Admati, DeMarzo, Hellwig, and Pfleiderer (2018) and Bahaj and Malherbe (forthcoming) for applications in a bank context.)
} 
Few papers have examined how shocks to investor demand affect the syndication process. An exception is the paper of Ivashina and Sun (2011), which looks at the time a loan spends in syndication as a proxy for demand and show how it relates to spreads. In contrast, we focus on how the terms of the loans are adjusted during the process, and use this to emphasize that demand discovery is a key function performed by arrangers.

Our paper provides a new perspective on why arrangers retain shares in syndicated loans. Ivashina and Scharfstein (2010) establish that aggregate downturns are associated with higher average retention by arrangers. Their broad interpretation is that this retention is due to a drop in aggregate demand for loans. Similarly, we establish that, at the loan level, negative demand shocks lead to larger retention by the arranger. Our results on demand discovery indicate that this retention is driven by the need to ration investors to preserve incentives in the demand discovery process. In contrast, following Sufi (2007), most of the literature notes that arrangers hold larger initial shares in loans to informationally opaque borrowers and interprets such shares as a commitment to monitor the borrower. ${ }^{4}$

Our paper also differs from this strand of literature in that we study leveraged loans, with a large focus on institutional term loans, and we use lender shares from SNC. In contrast, the literature that examines arranger shares has so far relied on lender share data from Thomson Reuters' DealScan, in which investment-grade credit lines constitute a large share of the data. Other aspects of syndicated lending examined in the literature include the propensity to syndicate a loan (Dennis and Mullineaux, 2000), final spreads and fees (Angbazo, Mei, and Saunders, 1998; Ivashina, 2009; Berg, Saunders, and Steffen, 2016; Cai, Eidam, Saunders, and Steffen, 2018), covenants

\footnotetext{
${ }^{4}$ An arranger clearly will have greater incentives to monitor if it holds a larger share (Gustafson, Ivanov, and Meisenzahl, 2016). However, when it comes to leveraged term loans, arrangers can typically sell their initial shares in opaque over-the-counter secondary markets (Bord and Santos, 2012). Therefore, it is not clear whether, for such loans, the share initially retained by the arranger can serve as a reliable commitment to monitor. Monitoring incentives also could be ensured by nonloan exposures (Neuhann and Saidi, 2016).
} 
(Drucker and Puri, 2009), and final syndicate composition (Cai, Eidam, Saunders, and Steffen, 2018; Benmelech, Dlugosz, and Ivashina, 2012).

Finally, we draw on the literature on demand discovery. Benveniste and Spindt (1989) establish that underpricing and rationing are part of the optimal mechanism to elicit investors' private information, in the sense that it minimizes their expected rent. Biais and Faugeron-Crouzet (2002) solve for the optimal direct mechanism and identify its key features. They also show that a marketclearing Dutch auction is likely to leave more rent to investors, a case that illustrates the importance of rationing. The demand-discovery hypothesis and its implications have mainly been tested empirically in the context of stock initial public offerings (IPOs). Examples include Hanley (1993), Cornelli and Goldreich (2001), and Cornelli and Goldreich (2003). Leveraged loan pipeline risk is related to underwriting risk in public security offerings, for example, stock IPOs. However, while arrangers of leveraged loans typically need to provide guarantees before demand discovery takes place, equity underwriters effectively only offer guarantees after demand discovery has taken place and restrict the formal risk to minimal (overnight) exposure (Lowry, Michaely, and Volkova, 2017). ${ }^{5}$ Finally, mortgage securitizers face the risk that loans can become delinquent while still in the pipeline. Although this mortgage securitization risk has also been referred to as "pipeline risk" (Brunnermeier, 2009) or "warehousing risk" (Keys, Seru, and Vig, 2012), it is not related to demand discovery.

\section{Overview of the syndication process}

This section is based on a series of interviews with market participants and gives a simplified summary of the leveraged loan syndication process. In particular, we focus on the elements relevant

\footnotetext{
${ }^{5}$ Evidence suggests that IPO underwriters buy substantial numbers of shares in less successful IPOs in after-market price stabilization. However, they seem to eliminate much of the risk associated with this activity via overallotment options (Ellis, Roni, and O'Hara, 2000, see section 3).
} 
for describing risk-sharing between arrangers and borrowers. Figure 1 depicts the timing of the process.

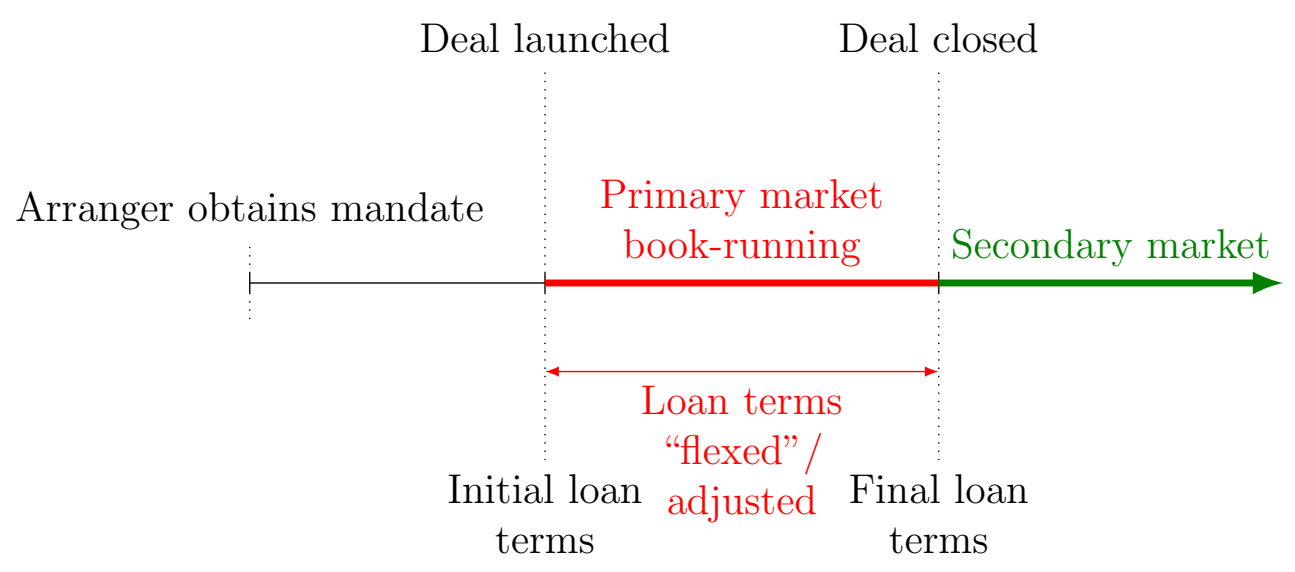

Figure 1. Syndication time line

This figure illustrates the time line for the leveraged term loan syndication process.

\subsection{The process}

\subsubsection{Competition for the mandate}

Issuers solicit bids from several potential arrangers, who compete on pricing, but also on how much insurance against demand risk they provide to the borrower. The borrower chooses an arranger and awards the mandate. Details of the mandate, including the details on the risk-sharing arrangement, are confidential, and, unfortunately, no data on such arrangements are publicly available.

\subsubsection{Book-running}

The arranger draws up a proposed facility agreement, which describes all the terms of the loan, including pricing, structure, the set of covenants, and their tightness, as well early repayment conditions. The deal then can be launched and a book runner, often an entity linked to the arranger, starts marketing the deal to investors on the basis of the facility agreement. 
The marketing takes place in one or more rounds. In each round, the arranger first proposes terms for the loan, including the spread, discount to par, potential covenants, etc. Investors can register an interest and are then given time to perform their credit analysis, after which they confirm whether or not they wish to invest at these terms. With the right amount of demand, the deal is successful and closed. If the deal is under- or oversubscribed, there is another round. The arranger uses feedback from investors to "flex," that is, to adjust the terms, for example, the interest rate or discount to par. Investors are then given time to consider whether they wish to invest at the new terms. Multiple rounds of adjustments and marketing can occur before the deal closes. In extreme cases when investors show very little interest, the arranger may decide to stop marketing the loan altogether, and the deal becomes a "hung deal." The book-running process typically takes several weeks (46 days on average in our sample of closed deals).

\subsubsection{Closing of the deal and secondary market}

Once the arranger has established which investors will participate in the deal, the final loan document can be signed, and the deal is closed. The borrower receives the funds and trading of the loan in the secondary market can commence.

\subsection{Risk-sharing}

Historically, leveraged loans were arranged either via an "underwritten" deal or via a "best efforts" deal. In an underwritten deal, the arranger would guarantee the terms of the loan to the borrower, including the total amount raised, and so would bear all the demand risk. If it was not possible to raise the required amount at the guaranteed terms from the market, the arranger would have to supply the rest. In a best efforts deal, the arranger would make no such guarantees, so the borrower would face the risk of possible changes to the terms and so bear the demand risk.

Nowadays, underwritten deals typically include so-called "flex provisions," which allow the 
arranger to make limited changes to the terms of the loan at the expense of the borrower. However, the arranger often has to give up a part of its fee before being allowed to invoke flex provisions. Furthermore, flexes that go further than the agreed limit are made at the expense of the arranger. This means that nowadays, when market participants speak of "underwritten" deals, they really refer to deals in which risks are shared between the arranger and the borrower. When there is no risk of confusion, we will adopt the same terminology. ${ }^{6}$

The key component of flex provisions typically is the maximum amount by which an arranger may increase either the spread over LIBOR or the discount to par at which the loan is issued. Flex provisions may also allow the arranger to adjust the loan amount. This is, for instance, common in dividend recapitalization deals but much less likely for a leveraged buyout (LBO) or an acquisition, where making a bid requires a certain amount. A "reverse flex" provision may also stipulate how gains are split between the arranger and the borrower when demand is higher than expected.

Arranger fees for underwritten deals (with flex provisions) tend to be in the range of $2 \%-3 \%$ of face value, whereas fees for best efforts deals are around $0.25 \%{ }^{7}$ The difference of about $1.75 \%^{-}$ $2.75 \%$ could be interpreted as an insurance premium paid to the arranger for the (partial) insurance that is provided.

\subsubsection{Risk-sharing: An example}

Suppose an arranger markets an underwritten loan with a face value of $\$ 100 \mathrm{~m}$. The arranger initially attempts to sell 20 'tickets' of $\$ 5 \mathrm{~m}$ each, at an interest rate of LIBOR +450 bps and with a discount of $1 \%$ to par. Following market convention, we compute the effective yield on the loan

\footnotetext{
${ }^{6}$ The underwriting practice for bonds differs and will often involve bridge loans. In that case, escalating price terms on the bridge loan can take a role similar to that of flex provisions when it comes to protecting an underwriter against situations with low demand for the security or loan.

${ }^{7}$ To our knowledge, no deal-specific data on actual arranger's fees are publicly available. Dealogic provides deal-specific fees, but these are imputed. These imputed fees are generally within the range that we indicate here.
} 
as follows:

$$
\text { yield }=L I B O R+\text { spread }+\frac{\text { discount }}{4} .
$$

The idea behind this calculation is that the discount is amortized over an effective maturity of (on average) 4 years. $^{8}$ Hence, our loan has an effective yield of LIBOR +475 bps.

Suppose the mandate stipulates that if there is no flex, the arranger is to receive a fee of $2 \%$. The arranger is permitted to flex the yield by up to 125 bps contingent on the fee being reduced to 1.75\%. We now give some illustrative adjustments that the arranger might make to ensure sufficient investor demand. (Table 1 also summarizes the numbers.) If the initially proposed terms attract enough investors, the deal can be closed at those terms. The borrower receives $\$ 97 \mathrm{~m}$ (the face value net of the $1 \%$ discount and the $2 \%$ fee) and will have to pay an interest rate of LIBOR+450 bps on the face value. The arranger receives the full fee $(\$ 2 \mathrm{~m})$.

If these terms do not attract enough investors, the arranger will have to invoke the flex provision and accept a reduced fee of $\$ 1.75 \mathrm{~m}$. The arranger could then propose a higher interest rate of, for instance, LIBOR+500 bps. If this is sufficient to entice investors, the deal closes. The borrower receives $\$ 97.25 \mathrm{~m}$ up front but now has to pay a higher interest rate of LIBOR +500 bps on the face value.

If these terms still do not attract enough investors, the arranger might try another round and increase the spread to LIBOR +550 bps and increase the discount from $1 \%$ to $2 \%$. This would bring the yield up to LIBOR+600 bps for a total flex of 125 bps (100 bps in spread and the equivalent of $25 \mathrm{bps}$ in discount). If the deal closes at these terms, the arranger receives a fee of $\$ 1.75 \mathrm{~m}$, and the borrower receives $\$ 96.25 \mathrm{~m}$ (the face value net of the $2 \%$ discount and the $1.75 \%$ fee) and will pay an interest rate of $\mathrm{LIBOR}+550 \mathrm{bps}$ on the face value.

The maximum flex permitted under the flex provision has now been reached. If these terms

\footnotetext{
${ }^{8}$ Four years is the effective maturity used for U.S. deals. For European deals, it is typically 3 years.
} 
still do not attract enough investors, the arranger is now on the hook for any further changes. For instance, the arranger may increase the discount again from $2 \%$ to $4 \%$, to raise the yield to LIBOR +650 bps. If the deal closes at these terms, the borrower will still receive $\$ 96.25 \mathrm{~m}$ and pay an interest rate of $\mathrm{LIBOR}+550 \mathrm{bps}$ on the face value, but the arranger has to finance the additional $2 \%$ of discount $(\$ 2 \mathrm{~m})$ out of its own pocket, and is now $\$ 0.25 \mathrm{~m}$ in the red.

Note that, at any point during the process, the arranger can decide to take a share of the loan on its balance sheet. In the extreme case of a hung deal, the arranger absorbs it in full. ${ }^{9}$

\section{Table 1}

\section{Risk-sharing via flex: An example}

This table illustrates how an arranger may adjust terms of a loan with a face value of $\$ 100 \mathrm{~m}$, an initially proposed interest rate of LIBOR+450 bps, an initial discount to par of $1 \%$, and an arranger fee of $2 \%$. We follow U.S. market convention and define the yield as reference rate plus spread plus discount divided by 4 . We have assumed that the flex provision stipulates that the arranger can increase the yield by up to 125 bps once it gives up $0.25 \%$ of its fee. Improvements beyond the maximum permitted flex under the provision happen at the expense of the arranger.

\begin{tabular}{r|c|c|r|r|c|c} 
Round & $\begin{array}{c}\text { Face } \\
\text { value }\end{array}$ & $\begin{array}{c}\text { Net } \\
\text { fee }\end{array}$ & Discount & $\begin{array}{c}\text { Borrower } \\
\text { receives }\end{array}$ & $\begin{array}{c}\text { Interest } \\
\text { rate }\end{array}$ & Yield \\
\hline 1 & $\$ 100 \mathrm{~m}$ & $\$ 2.00 \mathrm{~m}$ & $\$ 1 \mathrm{~m}$ & $\$ 97.00 \mathrm{~m}$ & $\mathrm{~L}+450 \mathrm{bps}$ & $\mathrm{L}+475 \mathrm{bps}$ \\
\hline 2 & $\$ 100 \mathrm{~m}$ & $\$ 1.75 \mathrm{~m}$ & $\$ 1 \mathrm{~m}$ & $\$ 97.25 \mathrm{~m}$ & $\mathrm{~L}+500 \mathrm{bps}$ & $\mathrm{L}+525 \mathrm{bps}$ \\
\hline 3 & $\$ 100 \mathrm{~m}$ & $\$ 1.75 \mathrm{~m}$ & $\$ 2 \mathrm{~m}$ & $\$ 96.25 \mathrm{~m}$ & $\mathrm{~L}+550 \mathrm{bps}$ & $\mathrm{L}+600 \mathrm{bps}$ \\
\hline 4 & $\$ 100 \mathrm{~m}$ & $-\$ 0.25 \mathrm{~m}$ & $\$ 4 \mathrm{~m}$ & $\$ 96.25 \mathrm{~m}$ & $\mathrm{~L}+550 \mathrm{bps}$ & $\mathrm{L}+650 \mathrm{bps}$ \\
\hline
\end{tabular}

\section{Data}

We use two data sources: S\&P Capital IQ's Leveraged Commentary and Data (LCD) and the Shared National Credit (SNC) database. LCD contains data on the syndication process for leveraged loans. ${ }^{10} \mathrm{SNC}$ contains data on lender shares in syndicated loans.

\footnotetext{
${ }^{9}$ See Appendix A for some anecdotal evidence of such "hung" deals.

${ }^{10}$ Formally, S\&P defines a leveraged loan as a syndicated loan with either a non-investment-grade rating, or with a first or second lien and a spread of at least 125 bps over LIBOR.
} 


\subsection{Sample construction}

Our version of LCD contains information on 12,070 leveraged loan deals from January 1, 1999, until October 15, 2015, where each deal consists of one or more facilities. We conduct our main analysis at the deal level. The main variables of interest for our purposes are those that describe adjustments to prices, spreads, and amounts during the syndication process, collectively known as flex.

For our analysis, we use subsets of the LCD data. For simplicity, we always ignore a very small number of deals for which information on the arranger is missing, which have more than one arranger, or have more than one deal purpose, leaving 11,658 deals. For the first part of our analysis in Section 4, which involves computations relating to loan underpricing, we must then also restrict our sample to loans for which we have good coverage of data items related to pricing. Specifically, we require a secondary market price and original issue discount (see below) so that we can calculate underpricing, and the initially proposed yield or "talk yield" as a control. This restriction reduces the sample to 3,000 deals. We refer to this sample as the "underpricing sample."

Requiring information on pricing affects the types of deals that are included. First, LCD has better coverage of pricing-related items in later years. Consequently, our underpricing sample consists of deals in or after November 2008 only. Second, LCD is more likely to contain price data on some types of facilities within a deal. Specifically, facilities are classified as either "pro rata" or "institutional." The pro rata facilities are revolving credit facilities (i.e., credit lines) or amortizing term loans, traditionally bought by banks, and the institutional facilities are bullet term loans, traditionally bought by institutional investors. Presumably because institutional facilities are more likely to trade, LCD is more likely to contain secondary market prices for institutional facilities. All of the 3,000 deals for which we have pricing information include at least one institutional facility.

In the second part of our analysis, we require information on the shares that arrangers retain 
in the deals. Following the literature, we refer to the share that a (lead) arranger retains as the Lead share. We obtain these data from the SNC, which is an annual survey of syndicated loans carried out by the Board of Governors of the Federal Reserve System, the Federal Deposit Insurance Corporation (FDIC), the Office of the Comptroller of the Currency, and, until recently, the Office of Thrift Supervision. The program obtains confidential information from administrative agent banks on all syndicated loans exceeding $\$ 20$ million when shares of the loan are being held by at least 3 federally supervised institutions. Information on new and existing loans that meet these criteria is collected as of December 31 of each year. ${ }^{11}$

In the underpricing sample, we have to restrict ourselves to the deals for which we have good coverage of pricing-related items. Matching this sample with SNC would leave us with very few observations, and for the second part of our analysis in Section 4, we do not need all pricing-related items. For this reason, we construct another sample by matching the full 11,658 deals in LCD with a single lead arranger and single deal purpose to deals in SNC, using the borrower name, origination date, and deal amounts for term loans in both data sets. We call the resultant sample the "lead share sample." It contains 1,796 matched deals. ${ }^{12}$

\subsection{Description of the data}

Table 2 provides summary statistics. Differences between the two samples largely reflect the fact that the underpricing sample contains only deals from November 2008 and on, whereas the lead share sample contains deals before that date. Relative to the whole sample period, the deals on or after November 2008 tend to have higher deal amounts and spreads, are more likely to be rated ${ }^{13}$ or

\footnotetext{
${ }^{11}$ Information on the purpose of the SNC and on inclusion criteria is available online (www.federalreserve.gov/bankinforeg/snc.htm and www.newyorkfed.org/banking/reportingforms/ guidelines.pdf).

${ }^{12}$ It is likely that the drop in sample size when matching is related to the SNC inclusion criterion that loan shares need to be held by at least three supervised institutions. Most leveraged loans are sold to nonbanks.

${ }^{13}$ In both samples, when ratings are available, they are almost exclusively noninvestment grade, as is to be expected given the focus of LCD on leveraged loans. LCD also contains information about deal purposes.
} 
to involve a financial sponsor (such as a private equity group), and are much more likely to include at least one cov-lite facility.

\section{Table 2 Summary statistics}

The underpricing sample consists of deals in LCD for which both the OID and break price is observed, so that underpricing can be computed. The lead share sample consists of deals in LCD that can be matched to SNC. Amount is the sum of committed amounts across all facilities in a deal. Amount flex is the sum of the amount flexes on all facilities in a deal, relative to the initially proposed amount. Spread, OID, Break price, Spread flex, and OID flex are deal-level averages. Rated, Sponsored, and Cov-lite are dummies that indicate whether at least one facility within a deal is rated, is sponsored, or is classified as cov-lite, respectively. Eff. spread flex is the sum of Spread flex and OID flex divided by 4. We treat observations for which no flex is reported as observations with zero flex. Lead share is the arranger's share in sum of utilized amounts across all facilities in a deal.

\begin{tabular}{|c|c|c|c|c|c|c|c|c|c|c|c|}
\hline \multicolumn{12}{|c|}{ UNDERPRICING SAMPLE } \\
\hline & $\begin{array}{c}\text { Amount } \\
\text { (m USD) }\end{array}$ & $\begin{array}{r}\text { Spread } \\
\text { (bps) }\end{array}$ & Rated & Sponsored & Cov-lite & $\begin{array}{r}O I D \\
\text { (bps) }\end{array}$ & $\begin{array}{c}\text { Break } \\
\text { price }(\%)\end{array}$ & $\begin{array}{c}\text { Amount } \\
\text { flex (bps) }\end{array}$ & $\begin{array}{c}\text { Spread } \\
\text { flex (bps) }\end{array}$ & $\begin{array}{c}\text { OID } \\
\text { flex (bps) }\end{array}$ & $\begin{array}{l}\text { Eff. spread } \\
\text { flex (bps) }\end{array}$ \\
\hline Mean & 708 & 438 & 0.940 & 0.668 & 0.432 & 100 & 99.847 & 14 & 3 & 5 & 4 \\
\hline SD & 744 & 145 & & & & 133 & 1.292 & 165 & 42 & 85 & 55 \\
\hline$\overline{25 \%}$ & 275 & 325 & & & & 25 & 99.500 & 0 & -25 & -25 & -25 \\
\hline Median & 465 & 400 & & & & 75 & 100.125 & 0 & 0 & 0 & 0 \\
\hline $75 \%$ & 850 & 525 & & & & 100 & 100.500 & 0 & 0 & 0 & 0 \\
\hline $\mathrm{N}$ & 3,000 & 3,000 & 3,000 & 3,000 & 3,000 & 3,000 & 3,000 & 3,000 & 3,000 & 3,000 & 3,000 \\
\hline \multicolumn{12}{|c|}{ LEAD SHARE SAMPLE } \\
\hline & $\begin{array}{c}\text { Amount } \\
\text { (m USD) }\end{array}$ & $\begin{array}{r}\text { Spread } \\
\text { (bps) }\end{array}$ & Rated & Sponsored & Cov-lite & & $\begin{array}{l}\text { ad share } \\
(\%)\end{array}$ & $\begin{array}{l}\text { Amount } \\
\text { flex (bps) }\end{array}$ & $\begin{array}{c}\text { Spread } \\
\text { flex (bps) }\end{array}$ & $\begin{array}{c}\text { OID } \\
\text { flex (bps) }\end{array}$ & $\begin{array}{l}\text { Eff. spread } \\
\text { flex (bps) }\end{array}$ \\
\hline Mean & 669 & 343 & 0.758 & 0.602 & 0.146 & & 7.459 & 4 & -2 & 5 & -1 \\
\hline SD & 979 & 135 & 0.429 & 0.490 & 0.353 & & 12.456 & 80 & 36 & 51 & 43 \\
\hline $25 \%$ & 200 & 250 & & & & & 0.285 & 0 & -25 & 0 & -25 \\
\hline Median & 380 & 317 & & & & & 2.588 & 0 & 0 & 0 & 0 \\
\hline $75 \%$ & 750 & 413 & & & & & 9.303 & 0 & 0 & 0 & 0 \\
\hline $\mathrm{N}$ & 1,796 & 1,788 & 1,796 & 1,796 & 1,796 & & 1,796 & 1,796 & 1,796 & 1,796 & 1,796 \\
\hline
\end{tabular}

LCD also includes information on deal purpose. In the underpricing sample (the lead share sample), deals that refinance existing debt are the most common and represent $38.0 \%$ (32.6\%) of all deals, followed by acquisitions with 20.5\% (21.8\%), LBOs with $15.1 \%$ (22.8\%), and Dividend Recapitalizations with $7.6 \%(9.4 \%)$. So deals that finance transactions (acquisitions or LBOs) and are hence more likely to be underwritten together represent around $35 \%-40 \%$ of the deals in our two samples. 


\subsubsection{Information related to underpricing}

Two key data items allow us to compute underpricing. The first key data item is the so-called "original issue discount" (OID), sometimes also referred to as the "up-front fee." In our terminology, an OID of $x \%$ indicates that investors pay a price of $(100-x) \%$ of face value for the loan in the primary market. ${ }^{14}$ As opposed to up-front fees in other syndicated loans, OIDs in leveraged loans are not typically tiered by commitments, so that all lenders who participate in the primary market receive the same OID. We aggregate by averaging across the facility OIDs in a deal. The median OID at the deal level is $75 \mathrm{bps}$, with substantial variation across deals. ${ }^{15}$

The second key data item in the underpricing sample is the so-called "break price." The break price is defined as the first price observed in the secondary market after the deal is completed. LCD collects this from market participants as the average midpoint between bids and offers, where the bids and offers are required to have "reasonable" depth. ${ }^{16}$ We aggregate by averaging across the facility break prices in a deal. As indicated in Table 2, the median break price in the underpricing sample at the deal level is slightly above par.

\subsubsection{Information on lead shares}

In the lead share sample, we use lender shares from SNC. We define the Lead share as the dollar value of the arranger's share in term loans plus the share in the utilized part of credit lines, over the dollar value of term loan face value plus utilized part of credit lines. ${ }^{17}$

\footnotetext{
${ }^{14}$ Note that our use of the term OID differs from that of some market participants, who confusingly use OID to refer to the primary market price, $(100-x) \%$.

${ }^{15}$ Berg, Saunders, and Steffen (2016), who focus mostly on credit lines, argue that fees are an important part of the cost of debt. They report an average up-front fee of about 80 bps in their Table 1 , which is similar to our OID.

${ }^{16}$ Although we are told that no formal criteria are used, it was indicated to us that, for example, quotes with a depth of $\$ 3$ million on either side would be considered "reasonable."

${ }^{17}$ In robustness tests, we also use other measures of lead share, including a "committed" lead share, which is similarly defined, but on the basis of committed, rather than utilized, amounts. See Appendix D.2.2.
} 
The average lead share is $7.5 \%$, and the median is $2.6 \%$. These numbers are low in comparison to lead shares in DealScan but are consistent with the magnitudes of lead shares in SNC as described in other papers (Bord and Santos, 2012). A potential reason for the discrepancy relates to socalled "primary assignments," which are prearranged loan purchases on the origination date and at the primary market price, but which are structured as secondary market transactions. These allow offshore investors, such as CLOs, to avoid the tax implications of direct participation in the primary market. A portion of what DealScan reports as the share of the arranger will typically be sold immediately upon close via such primary assignments. From that point of view, the lead share reported in SNC appears to be the more appropriate measure. ${ }^{18}$

\subsubsection{Data on flex}

One of the key advantages of the LCD data is that it provides flex information. Our main set of independent variables relate to flexes on spreads, discounts (OID), and amounts. Increasing the OID or increasing the spread both make a loan more attractive to investors. We combine both pieces of information in a single variable that we call effective spread. The definition follows the logic by which market convention defines the effective yield (see Equation (1) in Section 2):

$$
\text { effective spread flex } \equiv \text { spread flex }+\frac{\text { OID flex }}{4} .
$$

We aggregate to the deal level by taking the average of the facility-level spread flex, the average of the facility-level OID flex, and by summing the facility-level amount flex within a deal. We also assume that when no flex is reported, this is because there is no flex.

Overall, we can see that the mean flexes tend to be very close to zero, especially when compared

\footnotetext{
${ }^{18}$ In addition, while DealScan contains lender shares for about $18 \%$ of all deals in DealScan, it contains lender shares for only about $4 \%$ of the leveraged loan deals that we consider here. This means that using DealScan as a source of lead share information when matching with LCD would result in only in a very small set of deals with both lead share and flex information and is therefore not useful. (A detailed discussion of these differences between LCD and DealScan is available from the authors on request.)
} 
to their standard deviations (see Table 2). The most likely type of flex to be observed is spread flex, which occurs in about $30 \%-55 \%$ of the deals within a given year. The least likely flex to be observed is amount flex, which occurs in about $20 \%-35 \%$ of the deals within a given year, with OID flex taking an intermediate position. Amounts and OIDs were less likely to be flexed before the global financial crisis, but are now more likely to be flexed. Again, this change over time implies that amounts and OIDs are more likely to be flexed in the more recent underpricing sample than in the longer lead share sample. We describe in more detail whether, when, and how loans are flexed in Appendix B.1.

\section{Theory and Testable Hypotheses}

To provide motivation for the tests we run, we present a simple model of demand discovery, in which an uninformed principal sells an asset to agents who have private information about their demand. This model replicates the standard point made by models of the IPO book building literature (Benveniste and Spindt, 1989): To maximize revenues from the sale of the loan, the arranger must give incentives to investors to reveal their true willingness to pay for the loan. The arranger does this by underpricing the loan when investors indicate that they are willing to pay high prices (and so leaves some money on the table), and by rationing the quantities that investors get when they indicate that they are willing to pay low prices. ${ }^{19}$

But our model also makes a new point, specific to leveraged loan context. Rationing investors means decreasing the amount of funds they provide. If investors provide less funds, then the arranger either has to decrease the loan amount received by the borrower, or retain a part of the loan itself (or a combination of both). What happens in practice depends on the risk sharing

\footnotetext{
${ }^{19}$ Technically, the model belongs to a well-studied class of mechanism design models (Guesnerie and Laffont, 1984; Maskin and Riley, 1984). The standard predictions of distortion at the bottom and rents at the top translate into rationing and underpricing, respectively.
} 
agreement between the borrower and the arranger. The simplest way to illustrate how this leads to new empirical predictions is to first consider the case of a fully underwritten deal. This is where we start. Then, we explain why the predictions also apply to partially underwritten deals (that is, to "underwritten deals" with flex provisions as discussed in Section 2), and how they contrast with the case of best effort deals.

\subsection{A simple model of underpricing and retention}

Consider an arranger who has fully underwritten a loan: she has promised the borrower that he will receive a loan of size 1 at a given interest rate. Without loss of generality, we normalize the underwriting fee to zero. Furthermore, to simplify, we assume a single potential investor in the loan. ${ }^{20}$ The market value of the loan, denoted $v$, is uncertain. It is either high, $v_{H}=1.2$, or low, $v_{L}=0.8$, with equal probability. If $p$ is the price at which the loan is sold to the investor, and $0 \leq q \leq 1$ is the proportion of the loan that the investor buys, his surplus is

$$
q(v-p)
$$

The arranger will offer a menu of different combinations of $p$ and $q$ to the investor. The arranger will retain any unsold part of the loan. We denote the share retained by the arranger as $r \equiv 1-q$. Retention is costly, so that the arranger's payoff is

$$
\pi=-1+p q+r v-\underbrace{\alpha r^{2} v}_{\text {retention cost }}
$$

The first term on the right-hand side $(-1)$ represents the funds provided by the arranger to the borrower. The second term $(p q)$ describes the proceeds from the quantity $q$ that is sold to the investor. The last two terms describe the value that the arranger attaches to retaining an amount $r \equiv 1-q$, net of (quadratic) retention costs, where the intensity of retention costs is described by

\footnotetext{
${ }^{20}$ This simplifying assumption (relative to Benveniste and Spindt (1989)) allows us to sidestep the issue of private versus common values and the issue of uniform versus nonuniform pricing.
} 
a parameter $\alpha>0$. Costly retention makes the investor the natural holder of the loan, such that it is optimal for the arranger to originate-to-distribute. Hence, under full information (that is, if $v$ becomes observable before the sale takes place), the arranger chooses to sell the whole loan, at the fair price: $q^{*}=1$ and $p^{*}=v$. In that case, we have

$$
\left\{\begin{array}{l}
\pi_{H}=0.2 \\
\pi_{L}=-0.2
\end{array}\right.
$$

Here, the variability in profit of the arranger simply reflects fundamental uncertainty about demand.

\subsubsection{Market-clearing fixed price}

Assume that the investor privately knows $v$, and that the arranger simply fixes a price and sells whatever quantity can be sold at that price. If the price is below 0.8 , the investor buys in the two states. If it is strictly above 0.8 , however, the investor only buys in the high state (as long as the price does not exceed 1.2). So the highest possible price at which the arranger sells the loan for sure, that is, the market-clearing price, is 0.8. At this market-clearing price, the payoffs to the arranger are

$$
\left\{\begin{array}{l}
\pi_{H}=-0.2 \\
\pi_{L}=-0.2
\end{array}\right.
$$

\subsubsection{Low-balling incentives}

Suppose instead that the arranger sets the price to 1.2 , and plans to only decrease the price if she cannot sell the loan at that price. The problem is that an investor with a high valuation will pretend not to be interested, because he understands that the arranger will then decrease the price to 0.8 . In that case, the price is always 0.8 , and the payoffs are identical to those with a market-clearing fixed price (see Equation (3)). 


\subsubsection{Demand discovery}

Now consider the mechanism design problem where the arranger offers the investor a menu of two possible price-quantity combinations to choose from, $\left\{\left\{p_{H}, q_{H}\right\},\left\{p_{L}, q_{L}\right\}\right\}$. Using the revelation principle, we can think of the arranger choosing this menu to maximize her expected payoff, subject to an incentive compatibility constraint and a participation constraint. The incentive compatibility constraint states that the investor must be "truthful," meaning that he must pick $\left\{p_{H}, q_{H}\right\}$ if he knows that the value is $v_{H}$, and $\left\{p_{L}, q_{L}\right\}$ if he knows that the value is $v_{L}$.

The investor's participation constraint simply states that the investor must want to participate and says that $p_{H} \leq 1.2$ and $p_{L} \leq 0.8$. The trickier problem for the arranger to address is to make sure that the investor does not feign low valuation: the payoff to an investor with a high valuation must be greater if he is truthful. Therefore, the incentive compatibility constraint (IC) is

$$
q_{H}\left(1.2-p_{H}\right) \geq q_{L}\left(1.2-p_{L}\right) .
$$

What is the optimal solution? First, the arranger has no reason to choose $p_{L}<0.8$ (because doing so would decrease her payoff and make incentives worse). Hence, she chooses $p_{L}^{*}=0.8$. Likewise, it is easy to show that there is no reason to set $q_{H}<1 .{ }^{21}$ So $q_{H}^{*}=1$. The IC constraint then reads

$$
\underbrace{1.2-p_{H}}_{\text {underpricing }}+0.4 \underbrace{\left(1-q_{L}\right)}_{\text {retention }} \geq 0.4
$$

which illustrates that both underpricing and retention play a role for incentives (as they help relax the constraint).

To find the optimal combination, we maximize $\pi$ subject to this constraint (and $p_{H} \leq 1.2$ ).

\footnotetext{
${ }^{21}$ The arranger payoff is obviously increasing in $q_{H}$ if the incentive constraint does not bind. But this is also true if it binds.
} 
The interesting case is when the retention cost is high enough, $\alpha \geq 0.25{ }^{22}$ We get

$$
\left\{\begin{array}{l}
p_{H}^{*}=1.2-0.1 \frac{4 \alpha-1}{\alpha} \\
q_{L}^{*}=1-\frac{1}{4 \alpha}
\end{array}\right.
$$

As anticipated, the optimal menu combines underpricing of hot deals $\left(p_{H}^{*}<1.2\right)$ and retention of cold deals $\left(q_{L}^{*}<1\right)$. This result does not hinge on there being two possible states only. It generalizes as follows: the hotter the deal, the more underpricing, the colder the deal, the larger retention. ${ }^{23}$ Finally, note that, as $\alpha$ increases, retention becomes more costly, and the arranger tends to retain less and underprices more.

\subsubsection{Retention and risk}

With demand discovery, the arranger's payoffs are

$$
\left\{\begin{array}{l}
\pi_{H}^{*}=-0.2+\frac{0.1}{\alpha} \\
\pi_{L}^{*}=-0.2-\frac{0.05}{\alpha}
\end{array}\right.
$$

Comparing these to the payoffs she receives if she uses a market-clearing fixed price (3), we can appreciate the benefits from demand discovery: while retention is costly for the arranger and decreases her payoff by an amount of $0.05 / \alpha$ in the low state, she gains double that amount in the high state. Put differently, without rationing, the investor's strategic low-balling forces the arranger to drastically underprice the good deals $\left(p_{H}^{*}=0.8\right)$. But with rationing, the arranger can improve incentives and leave less rent, in expectation, to the investor.

However, it is important to note that rationing goes together with magnifying downside risk: in the low state, without rationing, the profit is -0.2 , which simply reflects the risk that valuation is low. With rationing, the profit in that state is even lower, which reflects that retention is ex post

\footnotetext{
${ }^{22}$ If $\alpha<0.25$, we get $q_{L}^{*}=0$ and $p_{H}^{*}=1.2$. Here, retention is not so costly, and the arranger prefers to retain the whole loan in the low state in order to sell at the full price in the high state.

${ }^{23}$ For instance, considering an intermediary state $v_{M}$, we get $q_{L}^{*}<q_{M}^{*}<q_{H}^{*}=1$ and $0=\left(v_{L}-p_{L}^{*}\right)<$ $\left(v_{M}-p_{M}^{*}\right)<\left(v_{H}-p_{H}^{*}\right)$.
} 
inefficient. ${ }^{24}$ So, together with direct exposure to price adjustments (and lower fees, as explained in Section 2), the retention of cold loans should be interpreted as an adverse realization of pipeline risk.

\subsubsection{Partially underwritten deals and best effort deals}

So far, we have considered a fully underwritten loan. Now, let us consider the opposite extreme case of a best effort deal, where the whole burden of the risk is borne by the borrower. As mentioned above, this essentially correspond to the case studied in the IPO book building literature. Appendix C shows that our model can be rewritten in a way that leads to the exact same outcome for the investor (hence, the predictions on underpricing are unchanged), but where the arranger's payoffs become those of the borrower, and rationing translates into lower amounts issued instead of arranger retention. However, doing so would not generate a novel prediction, so we do not spell it out here.

In practice, deals are often somewhere between the two extremes of a fully underwritten deal and a best efforts deal. The borrower and the arranger will have a form of risk-sharing agreement (see Section 1). How the burden of underpricing and rationing is shared between the two parties will vary from deal to deal. As long as risks are shared, however, the arranger will receive a (weakly) lower payoff and will have to retain more shares whenever realized demand is lower.

The way practitioners describe typical flex provisions suggests that borrowers bear most of the burden of small price adjustments and arrangers bear most of the burden of large price adjustments. Regarding rationing, it depends on the borrower's flexibility with respect to the loan amount. An interesting case is that of deals associated with M\&As (i.e., LBOs and acquisitions). In such deals, the borrower needs certainty of funds to make a bid and therefore often has less flexibility than in, say, dividend recapitalizations or when refinancing an existing loan (the other two large categories

\footnotetext{
${ }^{24}$ As mentioned above, we have the standard predictions in this class of mechanism design problems: there are rents at the top (the investor gains $\left(1.2-p_{H}^{*}\right)>0$ in the high state) and distortion at the bottom $\left(q_{L}^{*}<1\right)$
} 
in our data). Hence, the risk associated with rationing will naturally be borne by the arranger. ${ }^{25}$

\subsection{Interpretation and hypotheses}

\subsubsection{Demand discovery and retention}

In the model, hot deals are underpriced $\left(p_{H}<1.2\right)$ and cold deals are not $\left(p_{L}=0.8\right)$. With more than two states, this generalizes to "the colder the deal, the less the loan is underpriced." In the context of IPOs, hot deals have been identified as those on which underwriters increase prices at the end of the book building process (Hanley, 1993). In our context, we can identify hot deals as those in which the arranger flexes the effective spread down, that is, either decreases the spread or the discount.

Hypothesis H1. On average, the flex in the effective spread is negatively related to underpricing.

This hypothesis reflects the so-called "partial adjustment phenomenon": prices do not fully adjust to revealed information. It is a unique prediction, so testing for partial adjustment is generally considered as the key step in establishing that demand discovery takes place (Benveniste and Spindt, 1989; Hanley, 1993). ${ }^{26}$

The second prediction is that investors are rationed on cold loans. As we have explained above, rationing on cold loans translates into arranger retention. Generally speaking, that the borrower also may bear some of the burden of rationing translates into lower amounts raised. However, in M\&A deals (i.e., LBOs and acquisitions), the borrower has less flexibility with respect to the amounts that need to be raised. ${ }^{27}$ For such deals, the arranger is likely to bear more (or all) of the

\footnotetext{
${ }^{25}$ For an example of such a risk-sharing agreement, see Section 1.

${ }^{26}$ For instance, consider the following alternative hypothesis: there is uncertainty about demand, but buyers do not know more about demand than the seller. The prediction of partial adjustment (H1) does not hold under this alternative hypothesis. This contrasts with the predictions in H2 and H3, which would also hold under this alternative hypothesis. In this sense, testing H2 and H3 by themselves would be insufficient to establish that demand discovery takes place.

${ }^{27}$ Market participants mentioned that there is, in fact, little flexibility on such deals. For instance, an
} 
rationing risk. We then get two testable hypotheses related to rationing:

Hypothesis H2. On average, the flex in the effective spread is negatively related to the flex in the amount. The relationship between effective spread flex and amount flex is less negative for MËA deals than for other types of deals.

Hypothesis H3. On average, the flex in the effective spread is positively related with arranger retention. The relationship between effective spread flex and amount flex is more negative for MËA deals than for other types of deals.

Hypotheses H1, H2, and H3 are at the heart of our analysis.

\section{Demand Discovery and Pipeline Risk: Evidence}

In this section, we first document that leveraged loans are underpriced on average and test the partial adjustment hypothesis (H1). Then we test the hypotheses related to rationing (H2 and H3). Together, the results show that arrangers of leveraged loans engage in demand discovery and expose themselves to pipeline risk, and, as such, represent the core of our paper.

\subsection{Underpricing and partial adjustment}

We follow the literature and assume that the first secondary market price reveals the true fundamental value, so that we can calculate underpricing of leveraged loans as follows:

$$
\text { underpricing }=\underbrace{\text { break price }}_{\text {secondary market price }}-\underbrace{(\text { par }- \text { original issue discount })}_{\text {primary market price }}
$$

LBO will likely require a given amount of financing. At the margin, it is possible to increase the proportion of equity financing relative to the proportion of loan financing. However, given the purpose of an LBO, this is typically perceived as quite costly. 
Each of the 3,000 deals in the underpricing sample has at least one facility for which we have both a break price and a discount. So, we can calculate a deal-level underpricing variable by taking the average underpricing across all facilities within the deal.

The median underpricing in our data is positive; it is equal to 75 bps of par (see Table B5 in Appendix B.2 for details). This number is lower than the $19 \%$ underpricing found for stocks (Jenkinson and Ljungqvist, 2001), comparable to the 47 bps underpricing found for speculativegrade bonds, ${ }^{28}$ and higher than the zero underpricing found for investment-grade bonds (Cai, Helwege, and Warga, 2007). We can test partial adjustment (Hypothesis H1) at the deal level by estimating the following equation:

$$
\text { Underpricing }_{i}=c+\beta_{1} \text { Effective spread flex } x_{i}+\gamma X_{i}+\epsilon_{i},
$$

where $X_{i}$ is a vector of loan characteristics that include the loan amount, maturity, initial yield, and dummies for whether the deal contains a revolving credit facility, is rated, is sponsored, includes a covenant-lite facility, or a second lien, as well as fixed effects for loan purpose, borrower industry, and deal month-year.

Hypothesis $\mathrm{H} 1$ translates into the prediction that the coefficient $\beta_{1}$ is negative. Table 3 presents our estimation results. Column 1 shows our baseline regression. As predicted, flexes in the spread have a negative and statistically significant effect on underpricing. The point estimates imply that a negative effective spread flex of 100 bps is associated with an increase in underpricing by about 7 bps. This reflects "partial adjustment" and therefore constitutes evidence that arrangers of leveraged loans engage in demand discovery, as do underwriters in equity IPOs (Hanley, 1993). In this baseline specification, we include time (month-year) fixed effects, to control for aggregate

\footnotetext{
${ }^{28}$ Because the break price that we have is a midpoint and bid-ask spreads are substantial, the actual profit that a primary market participant could make by buying in the primary market and selling at the bid is going to be lower. With a typical bid-ask spread of about $75 \mathrm{bps}$, the profit would be about 37.5 bps.
} 


\section{Table 3 \\ Underpricing and effective spread flex}

This table regresses underpricing on effective spread flex at the deal level. Underpricing and Eff. spread flex are measured in basis points of par. Eff. spread flex is the change in effective spread (see Equation (2)). RC, Rated, Sponsored, Cov-lite, and Second lien are dummies that indicate whether the deal contains a facility that is a revolving credit facility, is rated, is sponsored, or is classified as cov-lite or a second lien, respectively. $\log$ (Maturity) is the $\log$ of the average maturity of facilities. $\log$ (Talk amount) is the $\log$ of the initially proposed total deal amount. $\log ($ Talk yield $)$ is the log of the average of the initially offered all-in yield to maturity across all facilities. Time fixed effects are month-year fixed effects.

\begin{tabular}{lrr}
\hline \hline & \multicolumn{1}{c}{$(1)$} & \multicolumn{1}{c}{$(2)$} \\
\hline Eff. spread flex & $-0.0664^{* * *}$ & $-0.0701^{* * *}$ \\
& $(0.0196)$ & $(0.0190)$ \\
$R C$ & $6.009^{* * *}$ & $6.368^{* * *}$ \\
& $(1.817)$ & $(1.888)$ \\
Rated & $10.03^{* *}$ & $8.228^{* *}$ \\
& $(4.010)$ & $(3.756)$ \\
Sponsored & $-10.44^{* * *}$ & $-10.46^{* * *}$ \\
& $(2.205)$ & $(2.176)$ \\
Cov-lite & $4.354^{* *}$ & $4.782^{* *}$ \\
& $(1.925)$ & $(1.987)$ \\
Second lien & $-6.620^{*}$ & -5.609 \\
& $(3.401)$ & $(3.372)$ \\
$\log ($ Maturity $)$ & 0.214 & -0.466 \\
& $(4.280)$ & $(4.425)$ \\
$\log ($ Talk amount $)$ & $3.188^{* * *}$ & $3.240^{* * *}$ \\
& $(1.039)$ & $(1.082)$ \\
$\log$ (Talk yield $)$ & $79.43^{* * *}$ & $78.18^{* * *}$ \\
& $(6.381)$ & $(6.123)$ \\
Arranger FE & Yes & No \\
Arranger-Year FE & No & Yes \\
Purpose FE & Yes & Yes \\
Industry FE & Yes & Yes \\
Time FE & Yes & Yes \\
\hline Observations & 3,000 & 3,000 \\
$R^{2}$ & .415 & .461 \\
\hline \hline
\end{tabular}

Standard errors are in parentheses.

SEs are clustered by syndication month.

${ }^{*} p<.10 ;{ }^{* *} p<.05 ;{ }^{* * *} p<.01$. 
demand for syndicated loans and time-varying aggregate risk appetite. We also include arranger fixed effects, as arrangers may specialize in deals that require specific syndication strategies, and these deals may therefore differ in underpricing.

In Column 2, we replace arranger fixed effects with arranger-year fixed effects, to allow for changes over time in the types of deals or strategies that arrangers specialize in. This essentially does not affect the coefficient on effective spread flex. We provide more variations of these regressions in Appendix D.2, where we confirm, for instance, that net inflows into funds that invest into leveraged loans are a good proxy for aggregate demand as suggested by Ivashina and Sun (2011). In Appendix D.3, we furthermore discuss a potential sample selection issue: in principle, it is possible that loans that are cold in the primary market are subsequently less likely to trade in the secondary market. This might imply that we do not observe a break price for such deals, and hence cannot compute underpricing. In short, we find that the availability of break prices is not related to spread flex once we control for deal amount, whether there is rating, and initial yield as a proxy for the riskiness of the deals.

\subsection{Rationing and pipeline risk}

We test Hypothesis $\mathrm{H} 2$ by estimating the following equation:

$$
\text { Amount flex } x_{i}=c+\beta_{3} \text { Effective spread flex }+\beta_{4} \text { Effective spread flex } x_{i} \times M \& A+\gamma X_{i}+\epsilon_{i} \text {. }
$$

Here, Amount Flex is the difference between the initially proposed and final deal amounts, and is measured relative to the initially proposed amount (in basis points). $M \mathscr{G} A$ is a dummy that is one if the purpose of the deal is an acquisition or an LBO. As before, $X_{i}$ is the vector of loan characteristics. The prediction is that $\beta_{3}$ is negative and that $\beta_{4}$ is positive. We do not require lead shares, so we can use the underpricing sample (which is larger than the lead share sample). Table 4 presents the results. 


\section{Table 4}

\section{Amount flex and effective spread flex}

This table regresses Amount flex on Eff. spread flex at the deal level using the underpricing sample. Amount flex is measured as basis points of the initially proposed (talk) amount, and Eff. spread flex is measured in basis points of par. MESA is a dummy that is 1 when the deal purpose is acquisition or LBO. RC, Rated, Sponsored, Cov-lite, and Second lien are dummies that indicate whether the deal contains a facility that is a revolving credit facility, is rated, is sponsored, or is classified as cov-lite or a second lien, respectively. $\log$ (Maturity) is the $\log$ of the average maturity of facilities. $\log$ (Talk amount) is the log of the initially proposed total deal amount. $\log$ (Talk yield) is the log of the average of the initially offered all-in yield to maturity across all facilities. Time fixed effects are month-year fixed effects.

\begin{tabular}{lcccc}
\hline \hline & $(1)$ & $(2)$ & $(3)$ & $(4)$ \\
\hline Eff. spread flex & $-2.718^{* * *}$ & $-3.570^{* * *}$ & $-2.839^{* * *}$ & $-3.633^{* * *}$ \\
MEGA $\times$ Eff. spread flex & $(0.421)$ & $(0.636)$ & $(0.420)$ & $(0.649)$ \\
& & $2.043^{*}$ & & $1.908^{*}$ \\
$R C$ & & $(1.054)$ & & $(1.096)$ \\
& $-256.5^{* * *}$ & $-257.8^{* * *}$ & $-242.6^{* * *}$ & $-244.0^{* * *}$ \\
Rated & $(72.89)$ & $(72.47)$ & $(74.50)$ & $(73.91)$ \\
& 40.02 & 37.84 & 74.23 & 73.14 \\
Sponsored & $(79.49)$ & $(79.81)$ & $(86.08)$ & $(86.10)$ \\
& -132.3 & -130.4 & -131.2 & -128.7 \\
Cov-lite & $(105.7)$ & $(106.1)$ & $(111.0)$ & $(111.3)$ \\
& 134.1 & 132.2 & 131.1 & 129.2 \\
Second lien & $(87.62)$ & $(87.81)$ & $(87.81)$ & $(88.01)$ \\
& -3.418 & -12.56 & -23.27 & -30.62 \\
$\log ($ Maturity $)$ & $(76.74)$ & $(76.85)$ & $(76.86)$ & $(76.83)$ \\
& $518.3^{* *}$ & $518.5^{* *}$ & $452.7^{* *}$ & $454.3^{* *}$ \\
$\log ($ Talk amount $)$ & $(198.9)$ & $(199.0)$ & $(217.7)$ & $(217.4)$ \\
& $-179.5^{* * *}$ & $-178.8^{* * *}$ & $-183.9^{* *}$ & $-183.3^{* *}$ \\
$\log$ (Talk yield $)$ & $(67.02)$ & $(66.90)$ & $(72.34)$ & $(72.28)$ \\
& -63.61 & -58.45 & -15.42 & -13.01 \\
Arranger FE & $(158.7)$ & $(157.5)$ & $(167.8)$ & $(167.0)$ \\
Arranger-Year FE & Yes & Yes & No & No \\
Purpose FE & No & No & Yes & Yes \\
Industry FE & Yes & Yes & Yes & Yes \\
Time FE & Yes & Yes & Yes & Yes \\
\hline Observations & Yes & Yes & Yes & Yes \\
$R^{2}$ & 3,000 & 3,000 & 3,000 & 3,000 \\
\hline \hline
\end{tabular}

Standard errors are in parentheses.

SEs are clustered by syndication month.

${ }^{*} p<.10 ;{ }^{* *} p<.05 ;{ }^{* * *} p<.01$. 
Column 1 shows our baseline regression. As predicted, we find that amount flex is negatively related with effective spread flex. The estimate implies that when the effective spread is increased by 100 bps (corresponding to a move of about 1.8 standard deviations), on average, the amount is decreased by about $3 \%$ of the initially proposed amount. As before, this baseline specification includes arranger fixed effects, to control for potentially arranger-specific syndication strategies.

In Column 2, we introduce the interaction with our M\&A dummy. As predicted, the coefficient on the interaction term is positive: when a deal is cold, then the amount received by the borrower decreases by less for M\&A deals. (Speaking in relative terms, the borrower therefore receives more.)

In Columns 3 and 4, we rerun the two regressions, but replace arranger fixed effects with arranger-year fixed effects, to allow for potential time variation in arranger-specific syndication strategies. ${ }^{29}$ As we can see, the coefficients of interest are essentially identical to those in Columns 1 and 2 .

In short, this test constitutes further supportive evidence that leveraged loan syndication is a demand discovery exercise. (In that respect, this test is the counterpart of the result in table 3 , column 2 in Hanley (1993).) But it also suggests that borrowers face lower adjustment in quantities for M\&A deals. The goal in testing Hypothesis $\mathrm{H} 3$ is to assess to which extent the arranger is then on the hook.

We test Hypothesis H3 by estimating

$$
\text { Lead }_{\text {share }}=c+\beta_{5} \text { Effective spread flex }{ }_{i}+\beta_{6} \text { Effective spread flex } x_{i} \times \mathrm{M} \& \mathrm{~A}+\gamma X_{i}+\epsilon_{i},
$$

where Lead share is the share of the loan retained by the arranger. ${ }^{30}$ For this regression, we use the lead share sample, which contains data on lead shares from SNC (see Section 2). The prediction is

\footnotetext{
${ }^{29}$ Irani and Meisenzahl (2017) document that lenders' conditions mattered for loan sales during the financial crisis. Specifically, they find that lenders that heavily relied on wholesale funding precrisis sold more loan shares.

${ }^{30}$ We have also run this regression with different measures of retention. See the end of this subsection for a brief description and Appendix D.2 for details.
} 
that $\beta_{5}$ and $\beta_{6}$ are positive. Table 5 presents the results.

Our baseline regression, shown in Column 1, includes arranger fixed effects for the same reasons as above. As predicted, we find a positive and statistically significant coefficient on effective spread flex $\left(\beta_{5}\right)$. This means that arrangers do retain more of the cold loans. Column 2 introduces the interaction term. As predicted, we find a positive and statistically significant value for $\beta_{6}$. The value for $\left(\beta_{5}\right)$ in Column 1 implies that, on average, a 100-bp increase in the effective spread (about 1.8 standard deviations) is associated with an increase of about $2 \%$ in the lead share for the average deal. The results in Column 2 suggest that the effect is mainly driven by M\&A deals: taking the interaction into account, we only get an increase of about $0.6 \%$ for non-M\&A deals (and the coefficient is statistically insignificant), but the interaction term implies an additional $3 \%$ for M\&A deals. These magnitudes are economically large given a median lead share of only about $2.6 \%$ in our data. Overall, they provide support for our hypothesis.

Like for the previous tests, we also run more demanding specifications. In Columns 3 and 4, we repeat both regressions, but now use arranger-year fixed effects instead of arranger fixed effects. In Columns 5 and 6 , we control for $\log ($ Talk yield). Compared to Column 1 the coefficient on effective spread flex $\left(\beta_{5}\right)$ remains significant in Columns 3 and 5 and increases in magnitude (from $2 \%$ to $2.6 \%$ and $4.2 \%$, respectively). However, compared to Column 2 the coefficients on the interaction term $\left(\beta_{6}\right)$ stay large economically, but lose statistical significance. This may simply reflect a power issue as there are not enough deals per arranger-year to distinguish between M\&A and other types of deals. Finally, we note that $\log ($ Talk yield $)$ is only available for a small subset of observations in the lead share sample, so that the number of observations substantially drops in these specifications.

The SNC lead share is observed on December 31. Given the existence of an active secondary market, our data on the lead share may therefore not accurately reflect the share initially retained by the lead arranger. In particular Aramonte, Lee, and Stebunovs (Forthcoming) document that 
Table 5

Lead share and effective spread flex

This table regresses Lead share on Effective spread flex, at the deal level, using all deals in the lead share sample. Lead share is a fraction of par. Effective spread flex is in basis points of par. $M E A A$ is a dummy that is 1 when the deal purpose is acquisition or LBO. RC, Rated, Sponsored, Cov-lite, and Second lien are dummies that indicate whether the deal contains a facility that is a revolving credit facility, is rated, is sponsored, or is classified as cov-lite or a second lien, respectively. $\log$ (Maturity) is the $\log$ of the average maturity of facilities. $\log$ (Talk amount) is the $\log$ of the initially proposed total deal amount. $\log$ (Talk yield) is the log of the average of the initially offered all-in yield to maturity across all facilities. Time fixed effects are month-year fixed effects.

\begin{tabular}{|c|c|c|c|c|c|c|}
\hline & (1) & $(2)$ & $(3)$ & (4) & $(5)$ & (6) \\
\hline \multirow[t]{2}{*}{ Eff. spread flex } & $0.000196^{* *}$ & 0.0000583 & $0.000259^{* *}$ & 0.000161 & $0.000418^{* *}$ & 0.000313 \\
\hline & $(0.0000908)$ & $(0.0000834)$ & $(0.000109)$ & $(0.000102)$ & $(0.000208)$ & $(0.000200)$ \\
\hline \multirow[t]{2}{*}{$M \mathscr{G} A \times$ Eff. spread flex } & & $0.000302^{*}$ & & 0.000220 & & 0.000193 \\
\hline & & $(0.000168)$ & & $(0.000199)$ & & $(0.000346)$ \\
\hline \multirow[t]{2}{*}{$R C$} & $0.0363^{* * *}$ & $0.0361^{* * *}$ & $0.0405^{* * *}$ & $0.0402^{* * *}$ & $0.0538^{* * *}$ & $0.0537^{* * *}$ \\
\hline & $(0.00893)$ & $(0.00879)$ & $(0.0104)$ & $(0.0102)$ & $(0.0201)$ & $(0.0198)$ \\
\hline \multirow[t]{2}{*}{ Rated } & $-0.0210^{* * *}$ & $-0.0213^{* * *}$ & $-0.0233^{* * *}$ & $-0.0236^{* * *}$ & $-0.0446^{*}$ & $-0.0445^{*}$ \\
\hline & $(0.00765)$ & $(0.00763)$ & $(0.00768)$ & $(0.00762)$ & $(0.0232)$ & $(0.0231)$ \\
\hline \multirow[t]{2}{*}{ Sponsored } & -0.0153 & -0.0152 & -0.0132 & -0.0128 & -0.0245 & -0.0234 \\
\hline & $(0.00963)$ & $(0.00959)$ & $(0.00963)$ & $(0.00956)$ & $(0.0254)$ & $(0.0248)$ \\
\hline \multirow[t]{2}{*}{ Cov-lite } & -0.00910 & -0.00957 & -0.0168 & -0.0172 & -0.0267 & -0.0269 \\
\hline & $(0.0109)$ & $(0.0110)$ & $(0.0120)$ & $(0.0119)$ & $(0.0215)$ & $(0.0213)$ \\
\hline \multirow[t]{2}{*}{ Second lien } & 0.00366 & 0.00316 & 0.00445 & 0.00413 & 0.0168 & 0.0163 \\
\hline & $(0.00980)$ & $(0.00972)$ & $(0.0102)$ & $(0.0102)$ & $(0.0322)$ & $(0.0320)$ \\
\hline \multirow[t]{2}{*}{$\log ($ Maturity $)$} & -0.0201 & -0.0195 & -0.0160 & -0.0161 & -0.0432 & -0.0448 \\
\hline & $(0.0170)$ & $(0.0170)$ & $(0.0207)$ & $(0.0207)$ & $(0.0615)$ & $(0.0616)$ \\
\hline \multirow[t]{2}{*}{$\log ($ Talk amount $)$} & $-0.0163^{* * *}$ & $-0.0165^{* * *}$ & $-0.0148^{* * *}$ & $-0.0148^{* * *}$ & $-0.0215^{* *}$ & $-0.0219^{* *}$ \\
\hline & $(0.00363)$ & $(0.00361)$ & $(0.00404)$ & $(0.00403)$ & $(0.00975)$ & $(0.00967)$ \\
\hline \multirow[t]{2}{*}{$\log ($ Talk yield $)$} & & & & & 0.00893 & 0.00724 \\
\hline & & & & & $(0.0472)$ & $(0.0471)$ \\
\hline Arranger FE & Yes & Yes & No & No & No & No \\
\hline Arranger-year FE & No & No & Yes & Yes & Yes & Yes \\
\hline Purpose FE & Yes & Yes & Yes & Yes & Yes & Yes \\
\hline Industry FE & Yes & Yes & Yes & Yes & Yes & Yes \\
\hline Time FE & Yes & Yes & Yes & Yes & Yes & Yes \\
\hline Observations & 1,796 & 1,796 & 1,796 & 1,796 & 582 & 582 \\
\hline$R^{2}$ & .416 & .418 & .556 & .557 & .580 & .580 \\
\hline
\end{tabular}

Standard errors are in parentheses.

SEs are clustered by syndication month.

${ }^{*} p<.10 ;{ }^{* *} p<.05 ;{ }^{* * *} p<.01$. 
banks sell substantial parts of their term loan shares in the first quarter after origination. For this reason, our results are likely to underestimate the effect of flexes on lead shares. In Appendix D.2, Table D3, we repeat the same set of regressions as in Columns 1 to 6 in columns, but on a sample restricted to only those deal that take place in the final quarter of each year. The idea is that the bias must be smaller if banks had less time to sell down their positions. The point estimates imply stronger effects. For instance, focusing on the specification that corresponds to Column 1, we get an average increase of $3 \%$ (instead of $2 \%$ ). And in the one that corresponds to Column 2, we get an effect of close to $6 \%$ (instead of $3 \%$ ) for M\&A deals (and essentially zero for the others).

To facilitate comparison of our results to those in the literature, we have used retained shares as a dependent variable, calculated by dividing measures of retained amounts by total deal amounts. But Table 4 shows that final deal amounts are decreased on cold deals. So an increased lead share could, in principle, just reflect an unchanged retained amount out of a smaller deal amount. In Appendix D.2 (Tables D5 and D6), we confirm, however, that arrangers do indeed retain larger amounts in cold deals and that our results are essentially unchanged when we adjust our measure of lead share to neutralize this mechanical effect.

\subsection{Interpretation}

Together, the three results above constitute strong evidence that (a) demand discovery is a key economic function of arrangers of leveraged loans and (b) arrangers retain a larger fraction of the cold, less desirable loans, especially in M\&A loans. We note that this pipeline-risk-related reason for retention stands in sharp contrast with the reason that is most often emphasized in the literature, namely, the need to commit via retention to monitoring the borrower going forward (Sufi, 2007).

A natural follow-up question is whether there are consequences to pipeline risk. A typical worry for regulators is that adverse shocks to banks will make them contract credit supply. ${ }^{31}$ We will

\footnotetext{
${ }^{31}$ Pipeline risk is now included in some regulatory stress test exercises. For instance, according to its
} 
explore this hypothesis in the following section.

\section{Consequences of Pipeline Risk}

When the deals they arrange are hot, banks retain small shares and make money. When they arrange deals that turn out to be cold, they retain more and may lose money. Retention and losses tie up or erode a bank capital. A natural follow-up question then is whether experiencing more cold than hot deals is likely to affect the bank's future arranging and lending activities.

\subsection{Empirical specification}

Ideally, we would be able to directly measure the impact of adverse realizations of pipeline risk on the bank's regulatory capital. Unfortunately, this is not possible (for a start, data on risk sharing agreements are not available). So we construct a measure of overall deal coldness for a given arranger in a given quarter.

Concretely, we have identified cold deals as those for which the effective spread was flexed up, and hot deals as those for which the effective spread was flexed down. Correspondingly, we define "Coldness" at the bank level by adding the dollar amount of cold deals for that bank in a given quarter, and subtracting the dollar amount of hot deals. Our "cold-deal-channel" hypothesis is that an increase in Coldness causes a decrease in the ability of the affected bank to provide arranging services, and to provide credit. The data we have make directly establishing the existence of such a causal relation difficult. We proceed by testing an implication of the cold-deal-channel hypothesis. We believe this can provide plausible indirect support for our hypothesis, as we discuss in more detail below:

current governor, Mark Carney, the Bank of England imposed, on average, a 22\% loss rate on leveraged loans in banks' syndication pipelines in its latest stress test exercise. 
Hypothesis H4. Coldness (for an arranger in a given quarter) is negatively related with the bank's subsequent arranging activity and lending.

We regress outcome variables $Y_{i j t}$ that describe lending or arranging activity for a given bank $i$, in a given quarter $t$, and in a given industry $j$, on lagged Coldness, and on controls:

$$
Y_{i j t}=\beta_{7} \text { Coldness }_{i t-1}+\text { controls }+\epsilon_{i j t} .
$$

Hypothesis $\mathrm{H} 4$ describes that the Coldness ${ }_{i t-1}$ is negatively related to outcomes $Y_{i j t}$, so that the coefficient $\beta_{7}$ is negative.

We use two sets of controls. The first set of controls includes arranger fixed effects, time fixed effects, and industry-year fixed effects, to control for time-invariant differences across arrangers, fluctuations in aggregate demand, and differences in loan demand across industry and time. The second set of controls include a lagged dependent variable and time fixed effects, to account for potential serial correlation in $Y_{i j t}$ that is unrelated to Coldness, and fluctuations in aggregate demand. ${ }^{32}$ A priori, it is not clear whether time-invariant fixed effects or lagged dependent variables are the better modelling choice, and controlling for both could introduce bias. However, as Angrist and Pischke (2009) argue, the true coefficient is bounded by those obtained when controlling separately.

\subsection{Estimates}

Our first measure of subsequent bank activity is the total dollar amount of leveraged loan deals arranged by bank $i$ in quarter $t$ and industry $j$, constructed from LCD (Amount arranged). Columns

\footnotetext{
${ }^{32}$ To run these regressions, we partially balance the panel: industry-quarters with no activity (missing $\left.Y_{i j t}\right)$ are included with both Coldness $i t$ and $Y_{i j t}$ set to 0, unless the arranger in question has never been active in the industry in question (no observations $Y_{i j t}$ at all for arranger $i$ in industry $j$ ). We only fill industry-quarters between the first and the last arranging activity. Fully balancing the panel does not change the results. Dropping industry-quarters with no lending yields similar results.
} 


\section{Table 6}

\section{Coldness, arranging activity, and lending}

This table regresses Amount arranged (dollar amounts from LCD) and CL amount (dollar amounts of new credit line participations in deals arranged by other banks for which the bank in question is not the arranger, from SNC), on lagged Coldness, at the arranger-quarter-industry level. Coldness is defined as the difference between the dollar amount of deals with positive effective spread flex minus the dollar amount of deals with negative effective spread flex, of a given arranger, in a given quarter, in LCD. Time fixed-effects are at the syndication-quarter level.

\begin{tabular}{|c|c|c|c|c|}
\hline & $\begin{array}{c}(1) \\
\text { Amount arranged }\end{array}$ & $\begin{array}{c}(2) \\
\text { Amount arranged }\end{array}$ & $\begin{array}{c}(3) \\
C L \text { amount }\end{array}$ & $\begin{array}{c}(4) \\
C L \text { amount }\end{array}$ \\
\hline Coldness $_{t-1}$ & $\begin{array}{r}-0.0686^{* * *} \\
(0.00884)\end{array}$ & $\begin{array}{c}-0.0622^{* * *} \\
(0.00929)\end{array}$ & $\begin{array}{c}-0.00944^{* * *} \\
(0.00223)\end{array}$ & $\begin{array}{c}-0.0176^{* * *} \\
(0.00236)\end{array}$ \\
\hline Amount arranged $_{t-1}$ & & $\begin{array}{l}0.381^{* * *} \\
(0.0230)\end{array}$ & & \\
\hline$C L$ lending $_{t-1}$ & & & & $\begin{array}{l}0.508^{* * *} \\
(0.0244)\end{array}$ \\
\hline Arranger FE & Yes & No & Yes & No \\
\hline Industry-Year FE & Yes & No & Yes & No \\
\hline Time FE & Yes & Yes & Yes & Yes \\
\hline Observations & 18,289 & 18,289 & 15,344 & 15,344 \\
\hline$R^{2}$ & .311 & .251 & .509 & .383 \\
\hline
\end{tabular}

Standard errors are in parentheses.

SEs are clustered by quarter.

${ }^{*} p<.10 ;{ }^{* *} p<.05 ;{ }^{* * *} p<0.01$. 
1 and 2 of Table 6 show the results for this dependent variable, for our two sets of controls, respectively. The effect of lagged Coldness on Amount arranged is negative and significant in both specifications, and the magnitude of the coefficient is similar.

We can interpret the economic magnitude of the coefficient in Columns 1 and 2 as follows: for the average bank in our sample, a 1-standard-deviation increase in Coldness is associated with a drop of about $12 \%-13 \%$ in the amount it arranges in the following quarter. More specifically, the quarterly standard deviation of Coldness is about $\$ 663 \mathrm{~m}$. So, a coefficient of $-6.22 \%$ (to take the example of Column 2) implies a drop of about $\$ 41 \mathrm{~m}$ in the amount arranged per industry. The average number of industries across which deals are arranged is about 7 . So, we get a total drop, across industries of about $\$ 287 \mathrm{~m}$ per quarter, which represents $12 \%$ of the total amount arranged per quarter by the average bank $(\$ 2,415 \mathrm{~m})$.

We believe that our "cold-deal-channel" hypothesis is a plausible interpretation of these results: cold deals erode a bank's regulatory capital, which makes it less able (and/ or willing) to support arranging activities going forward. However, although we control for potential aggregate and industry-wide fluctuations in demand for arranging services, we cannot rule out that our estimates are picking up autocorrelated, bank-specific fluctuations in demand for arranging services. For instance, potential borrowers might view a bank as lacking in diligence if this bank experiences many cold deals in one quarter and then might be reluctant to have their deals arranged by this bank in the next quarter.

This is a concern that we cannot address directly when using arranging activity as a left-hand side variable. But we can look at future activities of the bank that are not directly related to their arranging activity, such as lending via "unrelated" credit lines: even if cold loans imply that a bank is an incompetent arranger of loans, that does not mean that a borrower would object to the bank holding a share in their credit line, provided that the credit line is arranged by a different 
bank. ${ }^{33}$ For borrowers to object, competence in arranging loans would have to be related to its ability to honor its commitments under a credit line. While we cannot rule this out, we find this interpretation less plausible.

To construct a measure of lending under unrelated credit lines, which we refer to as $C L$ Lending, by hand-matching arrangers in LCD to SNC. To do so, we restrict ourselves to the more active arrangers. We define these as arrangers who arranged loans in at least half of all quarters in the LCD data. This leaves us with the 17 active arrangers who together account for $88 \%$ of the leveraged term loan market. ${ }^{34}$ Columns 3 and 4 of Table 6 show the results for this dependent variable. The effect of lagged Coldness is negative and significant in both specifications, although this time, the magnitude of coefficients differs depending on the set of controls. (As noted above, Angrist and Pischke (2009) argue that the true effect should be bracketed by the two estimates.)

We can interpret the economic magnitude of the coefficient in Columns 3 and 4 as follows: for the average bank in our sample, a 1-standard-deviation increase in Coldness is associated with a drop of about $4 \%-8 \%$ in the amount of new participations by this arranger in unrelated credit lines in the following quarter. More specifically, the quarterly standard deviation of Coldness is here about $\$ 952 \mathrm{~m}$ (by construction, in the hand-matched sample, the average bank is more active). So, a coefficient of $-1.76 \%$ (to take the example of Column 4) implies a drop of about $\$ 17 \mathrm{~m}$ in lending via unrelated credit lines. As before, this number is per industry (and the arranger lends to 11 industries, on average). So this makes for a total drop of about $\$ 187 \mathrm{~m}$ per quarter, or $8 \%$ of the corresponding average total lending $(\$ 2,476 \mathrm{~m})$. The effect is economically significant and suggests, according to our interpretation, a meaningful spillover from pipeline risk in leveraged loans to other lending markets. Put simply: the results are also consistent with our cold-deal-channel

\footnotetext{
${ }^{33}$ Looking at unrelated term loans would be less interesting, because such loans are typically distributed to institutional investors rather than other banks.

${ }^{34}$ As noted above, one caveat is that the SNC only reports loan shares as of December 31st of the reporting year. We assign the year-end loan share to the respective origination quarter.
} 
hypothesis. ${ }^{35}$

We note, however, that we may be overestimating the effect of Coldness on either Amount Arranged or CL Lending: arrangers may suffer from cold deals at times when other events also have a negative effect on the bank's ability to arrange and lend. Time fixed effects and industry-time fixed effects control for many, but not all such events.

For instance, suppose a bank underwrites two deals simultaneously. Furthermore, suppose there is no appetite for either deal, but while the bank manages to close the first, the second deal becomes hung and does not close. LCD only reports on deals that closed, so we would not observe the second deal in our sample. Alternatively, suppose a bank underwrites a loan and a bond that both finance the same deal, which turns out to be cold. LCD only covers loans, so we would not observe the problems the bank might have in selling the bond. In either case, we would underestimate the true coldness, and would attribute all of the subsequent drop in arranging and lending to the part of coldness that we observe, which is only the "tip of the iceberg." Our estimates would be too large, but we would still be picking up an effect of deal coldness.

As noted in the introduction, regulators are asserting that arranging activities of some banks represent a macroprudential concern. Pipeline risk and our cold-deal-channel hypothesis provide a potential rationale for these concerns. A limitation of our data is that we do not observe the actual guarantees given by arrangers to borrowers. Underwriting agreements are confidential, and, to the best of our knowledge, regulators do not systematically collect information on such agreements. Our analysis suggests that doing so would be very useful for quantifying pipeline risk ex ante. Constructing a pipeline risk indicator on the basis of such information would (a) allow regulators

\footnotetext{
${ }^{35}$ Appendix D.4 shows that the magnitudes and significance of the coefficients for neither of our two dependent variables are driven by the period of the global financial crisis in 2008 and 2009. In unreported results, we also confirmed that the estimates are essentially unchanged when controlling for time-varying arranger characteristics, such as leverage, return on assets, size, and market-to-book ratios (measured as the $\log$ of assets). (Plosser and Santos (2018), for instance, use these variables to proxy for regulatory capital ratios.)
} 
to actively monitor pipeline risk at the bank and the aggregate level; (b) inform the severity chosen for stress test scenarios; and (c) be a relevant input to specific capital charges that could (and probably should) apply to loans in the pipelines of banks.

\section{Conclusion}

We use novel data to study the syndication of leveraged term loans. We show that (a) demand discovery is a key economic function of arrangers of leveraged loans and (b) arrangers retain a larger fraction of the cold, less desirable loans. We argue that such retention reflects pipeline risk and stands in sharp contrast with the retention that is often emphasized in the literature, namely retention that commits to monitoring (Sufi, 2007). The data also suggests that adverse realizations of pipeline risk may reduce the ability and willingness of banks to engage in lending or arranging activities going forward. 


\section{References}

Admati, A. R., P. M. DeMarzo, M. F. Hellwig, and P. Pfleiderer, 2018, "The Leverage Ratchet Effect," The Journal of Finance, 73, 145-198.

Angbazo, L. A., J. Mei, and A. Saunders, 1998, "Credit spreads in the market for highly leveraged transaction loans," Journal of Banking \& Finance, 22, 1249-1282.

Angrist, J. D., and J.-S. Pischke, 2009, Mostly Harmless Econometrics: An Empirist's Companion, Princeton University Press, Princeton.

Aramonte, S., S. J. Lee, and V. Stebunovs, Forthcoming, "Risk Taking and Low Longer-term Interest Rates: Evidence from the U.S. Syndicated Loan Market," Journal of Banking and Finance.

Bahaj, S., and F. Malherbe, forthcoming, "The Forced Safety Effect: How Higher Capital Requirements Can Increase Bank Lending," Journal of Finance.

Benmelech, E., J. Dlugosz, and V. Ivashina, 2012, "Securitization without adverse selection: The case of CLOs," Journal of Financial Economics, 106, 91-113.

Benveniste, L. M., and P. A. Spindt, 1989, "How investment bankers determine the offer price and allocation of new issues," Journal of Financial Economics, 24, 343-361.

Berg, T., A. Saunders, and S. Steffen, 2016, "The Total Cost of Corporate Borrowing in the Loan Market: Don't Ignore the Fees," Journal of Finance, 71, 1357-1392.

Biais, B., and A. M. Faugeron-Crouzet, 2002, "IPO Auctions: English, Dutch,... French, and Internet," Journal of Financial Intermediation, 11, 9-36. 
Bord, V. M., and J. A. C. Santos, 2012, "The Rise of the Originate-to-Distribute Model and the Role of Banks in Financial Intermediation," Federal Reserve Bank of New York Economic Policy Review, 18, $21-34$.

Brunnermeier, M. K., 2009, "Deciphering the Liquidity and Credit Crunch 2007-2008," Journal of Economic Perspectives, 23, 77-100.

Cai, J., F. Eidam, A. Saunders, and S. Steffen, 2018, "Syndication, Interconnectedness, and Systemic Risk," Journal of Financial Stability, 34, 105-120.

Cai, N. K., J. Helwege, and A. Warga, 2007, "Underpricing in the Corporate Bond Market," Review of Financial Studies, 20, 2021-2046.

Cornelli, F., and D. Goldreich, 2001, "Bookbuilding and strategic allocation," Journal of Finance, $56,2337-2369$.

Cornelli, F., and D. Goldreich, 2003, "Bookbuilding: How Informative Is the Order Book?," Journal of Finance, 58, 1415-1443.

Dennis, S. A., and D. J. Mullineaux, 2000, "Syndicated Loans," Journal of Financial Intermediation, $9,404-426$.

Dezember, R., and M. Wirz, 2013, "Banks Seeking to Sell Rue21 Debt at a Discount; Three Banks on Hook for $\$ 780$ million in Buyout Financing," Wall Street Journal, September 25.

Drucker, S., and M. Puri, 2009, "On Loan Sales, Loan Contracting, and Lending relationships," Review of Financial Studies, 22, 2835-2872.

Ellis, K., M. Roni, and M. O'Hara, 2000, "When the Underwriter Is the Market Maker: An Examination of Trading in the IPO Aftermarket," Journal of Finance, 55, 1039-1074. 
Esty, B. C., 2003, "Chase's Strategy for Syndicating the Hong Kong Disneyland Loan (A)," Harvard Business School Case Study 9-201-072.

Guesnerie, R., and J.-J. Laffont, 1984, "A complete solution to a class of principal-agent problems with an application to the control of a self-managed firm," Journal of Public Economics, 25, 329-369.

Gustafson, M., I. Ivanov, and R. Meisenzahl, 2016, "Bank Monitoring: Evidence from Syndicated Loans," Working Paper, Federal Reserve Board.

Hanley, K. W., 1993, "The underpricing of initial public offerings and the partial adjustment phenomenon," Journal of Financial Economics, 34, 231-250.

Irani, R., and R. Meisenzahl, 2017, "Loan Sales and Bank Liquidity Management: Evidence from a U.S. Credit Register," Review of Financial Studies, 30, 3455-3501.

Ishmael, S.-M., and H. Sender, 2008, "Loan market in 'disarray' after Harrah's upset," Financial Times, February 4.

Ivashina, V., 2009, "Asymmetric information effects on loan spreads," Journal of Financial Economics, $92,300-319$.

Ivashina, V., and D. Scharfstein, 2010, "Loan Syndication and Credit Cycles," American Economic Review, 100, 57-61.

Ivashina, V., and Z. Sun, 2011, "Institutional demand pressure and the cost of corporate loans," Journal of Financial Economics, 99, 500 - 522.

Jenkinson, T., and A. Ljungqvist, 2001, Going Public: The Theory and Evidence on How Companies Raise Equity Finance, Oxford University Press, Oxford, UK, 2nd edn. 
Keys, B. J., A. Seru, and V. Vig, 2012, "Lender Screening and the Role of Securitization: Evidence from Prime and Subprime Mortgage Markets," Review of Financial Studies, 25, 2071-2108.

Laughlin, K., 2010, "Covenant-lite loans are back but investors hope to limit mistakes of the past," Financial Times, November 24.

Lowry, M., R. Michaely, and E. Volkova, 2017, "Initial Public Offering: A Synthesis of the Literature and Directions for Future Research," Foundations and Trends in Finance, 11, 154-320.

Maskin, E., and J. G. Riley, 1984, "Monopoly with incomplete information," Rand Journal of Economics, 15, 171-196.

Myers, S. C., 1977, "Determinants of Corporate Borrowing," Journal of Financial Economics, 5, $147-175$.

Neuhann, D., and F. Saidi, 2016, "Bank Deregulation and the Rise of Institutional Lending," Working Paper, University of Texas at Austin.

Plosser, M. C., and J. a. A. C. Santos, 2018, "Banks' Incentives and Inconsistent Risk Models," Review of Financial Studies, 31, 2080-2112.

Rennison, J., and E. Platt, 2019, "Deutsche faces big hits on US leveraged-loan losses," Financial Times, June 25. https://www.ft.com/content/7ac67e18-9755-11e9-8cfb-30c211dcd229A.

Smith, R., and D. Scigliuzzo, 2015, "Underwriters on the hook after botched Veritas deal," Reuters, November 20. https://www.reuters.com/article/veritas-ma-carlyle-group-debt/ underwriters-on-the-hook-after-botched-veritas-deal-idUSL8N13D3Z620151120.

Sufi, A., 2007, "Information Asymmetry and Financing Arrangements: Evidence from Syndicated Loans," Journal of Finance, 62, 629-668. 
Wirz, M., 2015, "Warning for M\&A: Another Debt Deal Struggles; Goldman, J.P. Morgan run up against wary investors in attempt to shed leveraged loans," Wall Street Journal, October 6. https://www.wsj.com/articles/ goldman-j-p-morgan-struggle-to-sell-loans-backing-a-buyout-1444157502. 


\section{Appendix}

\section{A Anecdotal Evidence on Pipeline Risk}

In this appendix, we present some anecdotal evidence on pipeline risk.

- In February 2008, the syndication of $\$ 14$ billion debt used to finance the buyout of Harrah's Entertainment by Apollo Management and Texas Pacific Group collapsed. The group of banks syndicating the loan were not able to sell the LBO debt to third parties. The unsold debt remained on the banks' books, which in turn led to a sizable loss at a time when banks were already holding more than $\$ 150$ billion of unsyndicated, mostly LBO-related debt (Ishmael and Sender, 2008).

- In November 2010, Sports Authority refinanced a $\$ 275$ million bullet term loan that paid LIBOR +225 bps and had no LIBOR floor with a new, $\$ 300 \mathrm{~m}$ bullet term loan. The arranger, BofA Merrill Lynch, originally priced the loan at LIBOR +525 bps-550 bps along with a $1.5 \%$ LIBOR floor and a discount of $1 \%-2 \%$. However, because of low demand the terms had to be adjusted to LIBOR +600 bps with a discount of $3 \%$. Concurrently, the cell phone insurance provider Asurion had to sell debt with a discount of 4\%, a discount that was substantially higher than the initially proposed discount of $1 \%$ and also higher than the underwritten discount limit of the Barclays-led syndicate (Laughlin, 2010).

- In 2013, arrangers for the loan financing the buyout of Rue21 were on the hook for $\$ 780$ million and stood to lose up to $\$ 100$ million due to having to slash prices to place the underwritten loan with institutional investors (Dezember and Wirz, 2013)

- In October 2015, arrangers for the $\$ 1.2$ billion loan financing the buyout of FullBeauty were struggling to sell it (Wirz, 2015). According to the LCD data, placing this loan required an 
increase in the discount of $7.5 \%$ of face value.

- In November 2015, the Carlyle Group's buyout of Veritas collapsed when the arrangers, Bank of America Merrill Lynch and Morgan Stanley, could not place the LBO debt. One of the first adjustments the banks offered was to cut the size of the term loan B to $\$ 1.5$ billion from $\$ 2.45$ billion - moving $\$ 250$ million to bonds and retaining $\$ 700$ million themselves. With the new spreads well outside the initial range, investors knew the banks were on the hook. However, this offer did not sway investors. The underwriters then tried to sweeten the deal by raising the spread and offering a steeper discount of $5 \%$. When even these terms did not attract investors, the banks bumped up the discount to $10 \%$. After these efforts failed, the financing was subsequently pulled (Smith and Scigliuzzo, 2015). According to information provided to us by practitioners, the loans were not syndicated, but in the end had to be originated, so that the arrangers ended up with very large shares.

- In June 2019, Deutsche Bank faced multi-million-dollar losses within its U.S. investment banking unit after it struggled to offload two risky syndicated loans it had underwritten, both to back LBOs. In the end, the two deals were priced at 90 and 95 cents on the dollar, respectively. The Financial Times reported that the low price erased the fees that Deutsche would have earned on the transaction, but noted that it was not able to determine the exact size of the loss (Rennison and Platt, 2019). 


\section{B Additional Description of the Data}

\section{B.1 How and When Are Loans Flexed?}

Starting with all 11,658 deals in LCD with a single deal purpose and a single lead arranger, we plot the fraction of these deals for which effective spreads and amounts are flexed up or down by year in Figure B1. We can see in panel A that effective spreads are flexed frequently $(30 \%-55 \%$ of deals per year). Panel B indicates that amounts were unlikely to be flexed before the crisis, but that this practice has changed since the crisis; they are now flexed in about $20 \%-35 \%$ of deals. Flexing an

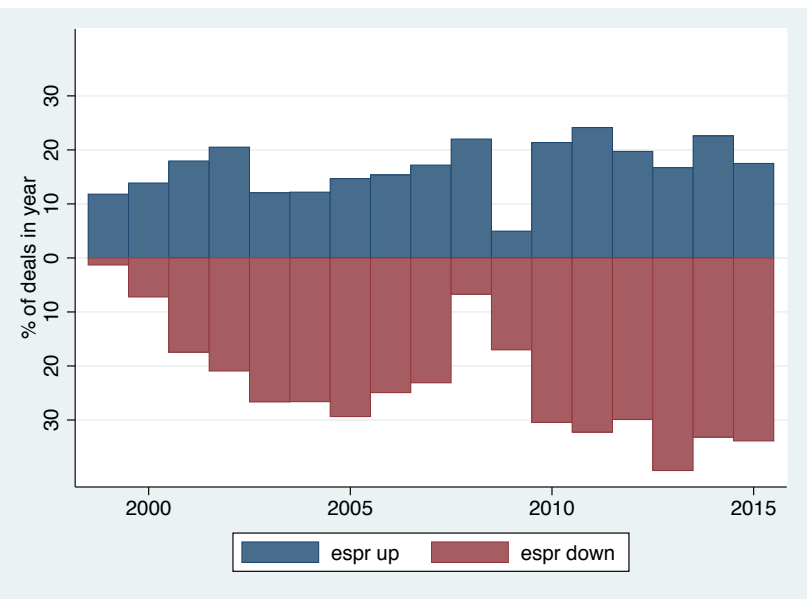

(a) Effective spread flex

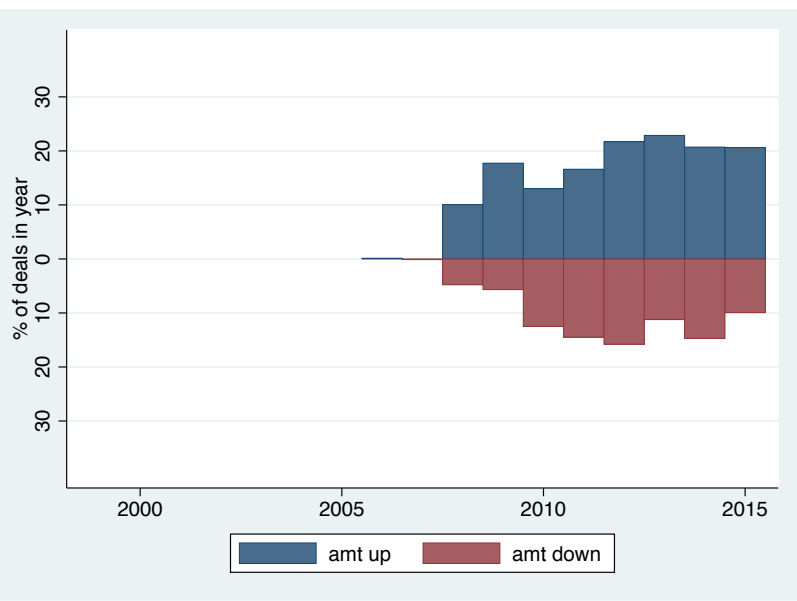

(b) Amount flex

Figure B1. Average up and down flex by year

Fraction of deals in our sample in a given year for which effective spreads and amounts are flexed up or down. Effective spreads are flexed frequently. Amounts were not flexed before the financial crisis, but are now being flexed, reflecting a change in market practice.

OID up or flexing a spread up both make a loan more attractive to investors. Do arrangers tend to flex OID and spread in the same direction or in opposite directions? Table B1 indicates that spreads are more likely to be flexed, and that when OIDs are flexed, they are flexed in the same direction as spreads. According to practitioners, arrangers primarily flex to meet investors' demand for yield (as defined in Equation (1)). They often start by increasing the spread, but, if necessary, 
eventually prefer to generate further increases in the yield via increases in the discount rather than by increases in the spread. This is because a very high spread can generate substantial prepayment risk. ${ }^{36}$ What determines when and whether loan terms are flexed? If the underlying reason is that

\section{Table B1}

\section{Relation between discount and spread flex}

Fraction of deals in our sample in which we observe spreads/ discounts being flexed down $(\downarrow)$ / not being flexed $(=) /$ being flexed up $(\uparrow)$, in percentage points.

\begin{tabular}{|l|rrr|r|}
\hline & Discount $\downarrow$ & Discount $=$ & Discount $\uparrow$ & Total \\
\hline Spread $\downarrow$ & 13.56 & 11.47 & 0.17 & 25.19 \\
Spread $=$ & 10.50 & 43.69 & 2.59 & 56.78 \\
Spread $\uparrow$ & 0.41 & 7.72 & 9.90 & 18.03 \\
\hline & 24.48 & 62.87 & 12.65 & 100.00 \\
\hline
\end{tabular}

the arranger does not know the ultimate demand for the loan, then we should probably observe more or bigger flexes, up and down, for loans for which demand should be more difficult to judge. Whether demand for a loan is more difficult to judge could relate to loan characteristics, such as the riskiness or purpose of the loan.

We first examine flexes in spreads. To describe how in our data, the probability and direction of spread flex relate to loan characteristics, we estimate a linear probability model, in which the dependent variable is either a dummy variable that is equal to 1 if the spread was flexed, or equal to 1 if the spread was flexed up only, or equal to 1 if it was flexed down only. Explanatory variables include $\log ($ Talk yield) (the initial all-in yield to maturity at the beginning of the syndication process; see also Equation (1)) and dummies that indicate whether the loan is made to finance an LBO or acquisition. We control for time-varying and marketwide institutional demand and overall risk appetite, by including either time fixed effects or fund and CLO flows. We also control for additional loan characteristics including a polynomial of the loan amount, whether the deal contains

\footnotetext{
${ }^{36}$ We were also told that accounting reasons (both on part of the lender or the borrower) could also influence the choice between providing yield via discount or spread.
} 
a revolving credit facility, is rated, is sponsored, includes a covenant-lite facility, or includes a second lien as well as fixed effects for loan purpose, borrower industry, and lead arranger. Table B2 shows the results from this estimation. Columns 1 and 2 show that loans with a high talk yield, loans that finance acquisitions or LBOs as opposed to refinancing existing loans, or loans that contain a revolving credit facility are more likely to experience spread flex. A possible interpretation is that for such more complex loans, the arranger finds it more difficult to anticipate the true demand for the loan and, hence, adjustments occur more frequently. In Columns 3 to 6 , we examine the direction of spread flex, by using as dependent variables dummies which are 1 when the spread is flexed up only (flexed down only) and show that these are related to net inflows into high-yield mutual funds and CLOs: in Column 4, we can see that net inflows, indicating high demand, are more likely to be associated with spreads being flexed down. In Column 6, we can see that net outflows, indicating low demand, are more likely to be associated with spreads being flexed up. Such inflows and outflows are contemporaneous and therefore not known to the lead arranger at launch.

We now turn to flexes in discounts. We first estimate a linear probability model in which the dependent variable is either a dummy variable that is equal to 1 if the discount was flexed, or equal to 1 if the discount was flexed up only, or equal to 1 if it was flexed down only. Table B3 shows the results of these estimations. As in the case of spread flex, we find that discounts are more likely to be flexed for loans with a high talk yield, or loans that finance Acquisitions or LBOs as opposed to refinancing existing loans. Again, a possible interpretation is that for such more complex loans, the arranger finds it more difficult to anticipate the true demand for the loan and, hence, adjustments occur more frequently. We can also see that discounts are more likely to be decreased when there are inflows into high-yield mutual funds and CLOs and more likely to be increased when there are outflows. Even though the results for the discount flexes are less statistically significant, they are 


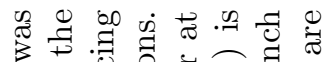

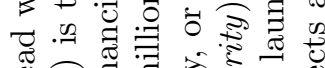

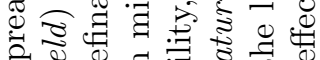

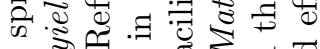
\&

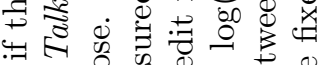
$\circ$ 으 $\exists$ 무 $\infty 0$ तี 导.

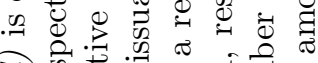
(2) क्षे जी दी ช.

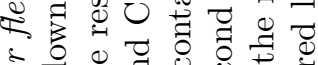

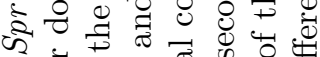
.

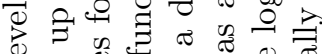

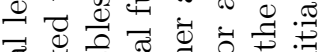
बె 0 世

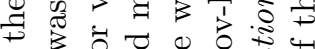
* का

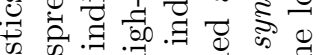
क 0 고

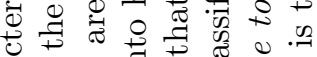
$\%$. $0 . \exists$ है

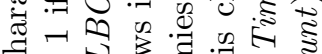

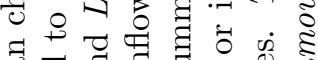

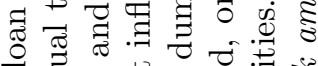
ఫㄹ

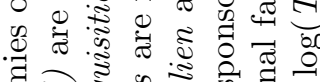

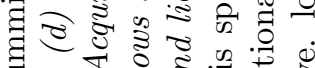

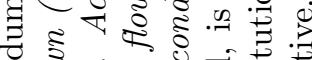

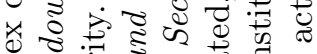
प

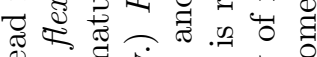

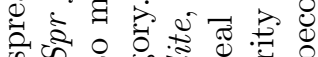
क人⿻8

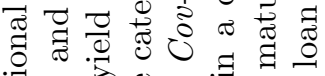

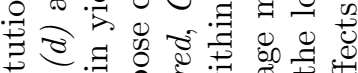
䓎

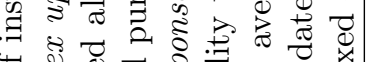

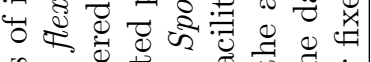

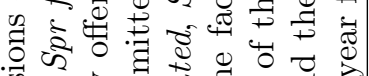

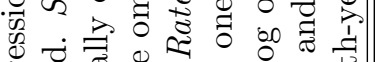
क人

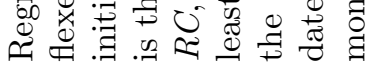

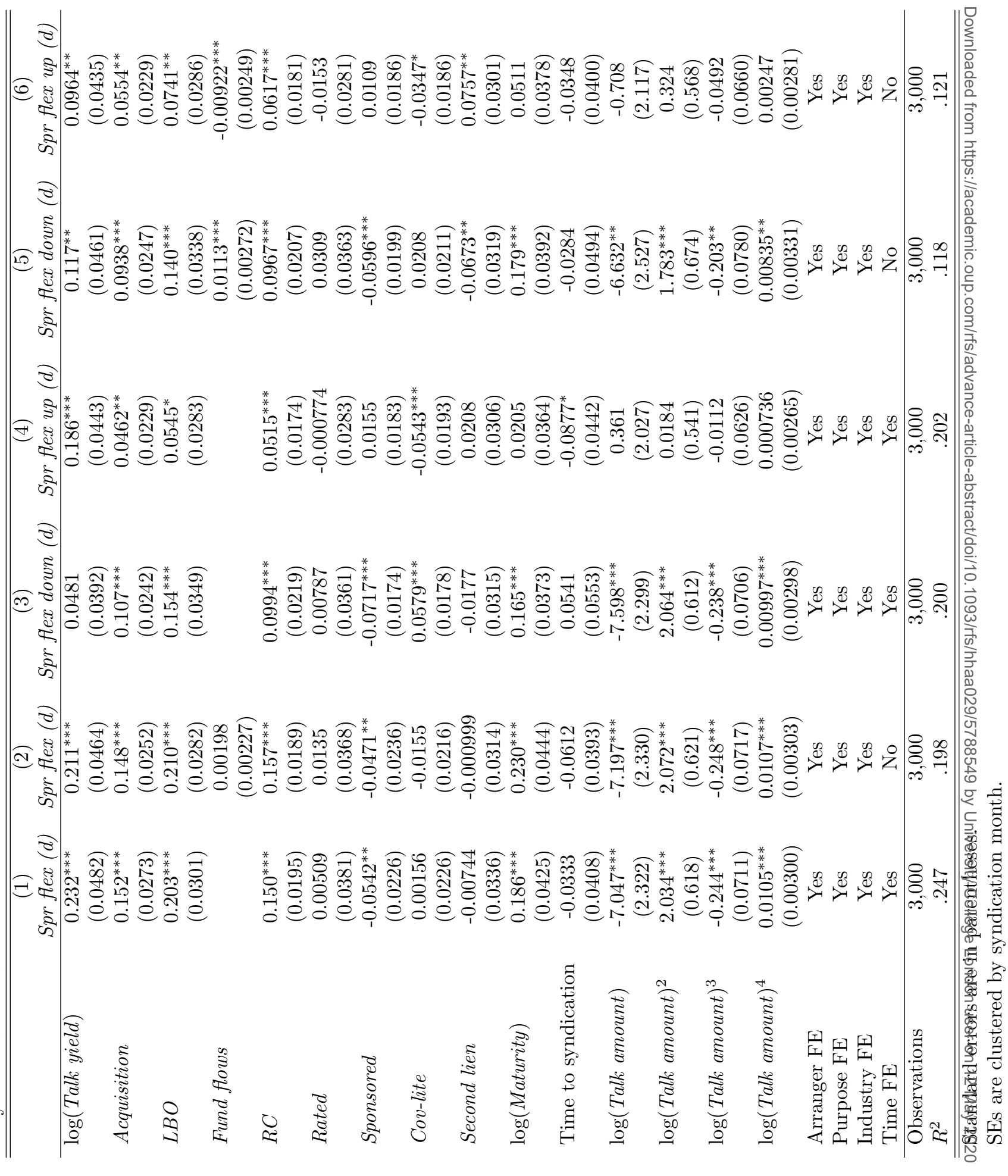


similar to those for spread flexes.

Finally, we examine flexes in amounts. We estimate a linear probability model in which the dependent variable is either a dummy variable that is equal to 1 if the institutional amount was flexed, or equal to 1 if the amount was flexed up only, or equal to 1 if it was flexed down only. Table B4 shows the results of these estimations. Here, we report an additional fixed effect related to the purpose of the deals: Eq. Payout is a dummy that is one if the purpose of the loan is to finance a dividend or share repurchase. In particular, in the syndication of such loans, amounts tend to be adjusted. (The omitted purpose category is refinancing.) 
苇芯 ठ․ㅐ

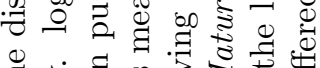

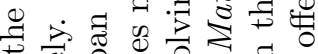

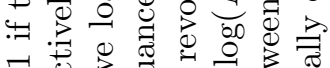

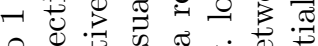
$\circ$ 过苑 త్ర

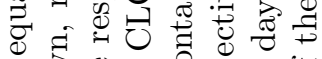
. ₹ 20.000

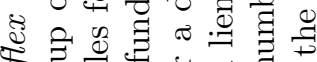

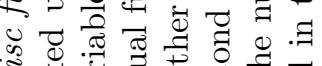

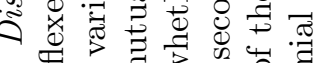
बं क

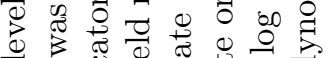

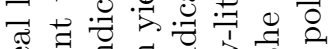
ष

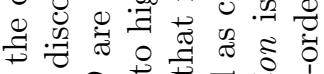

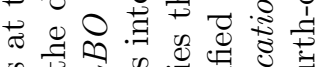
कु

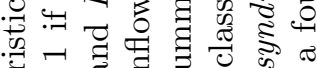

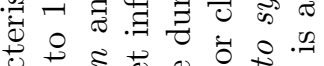

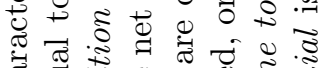

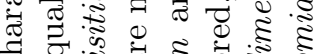

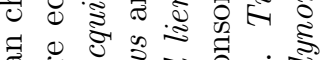
ฮี

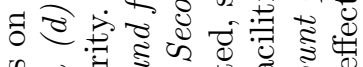

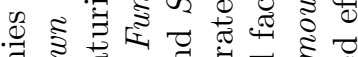

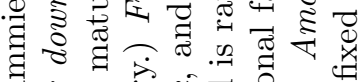

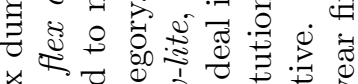
ช.

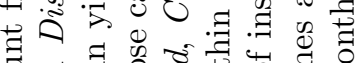

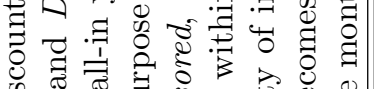

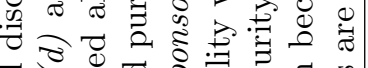
范芯 .

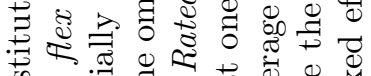

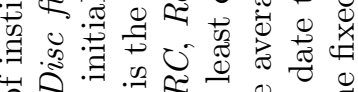
पे

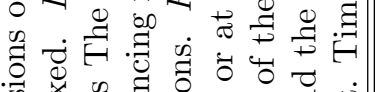

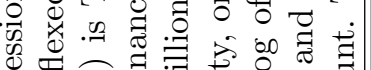

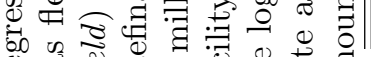

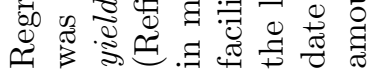

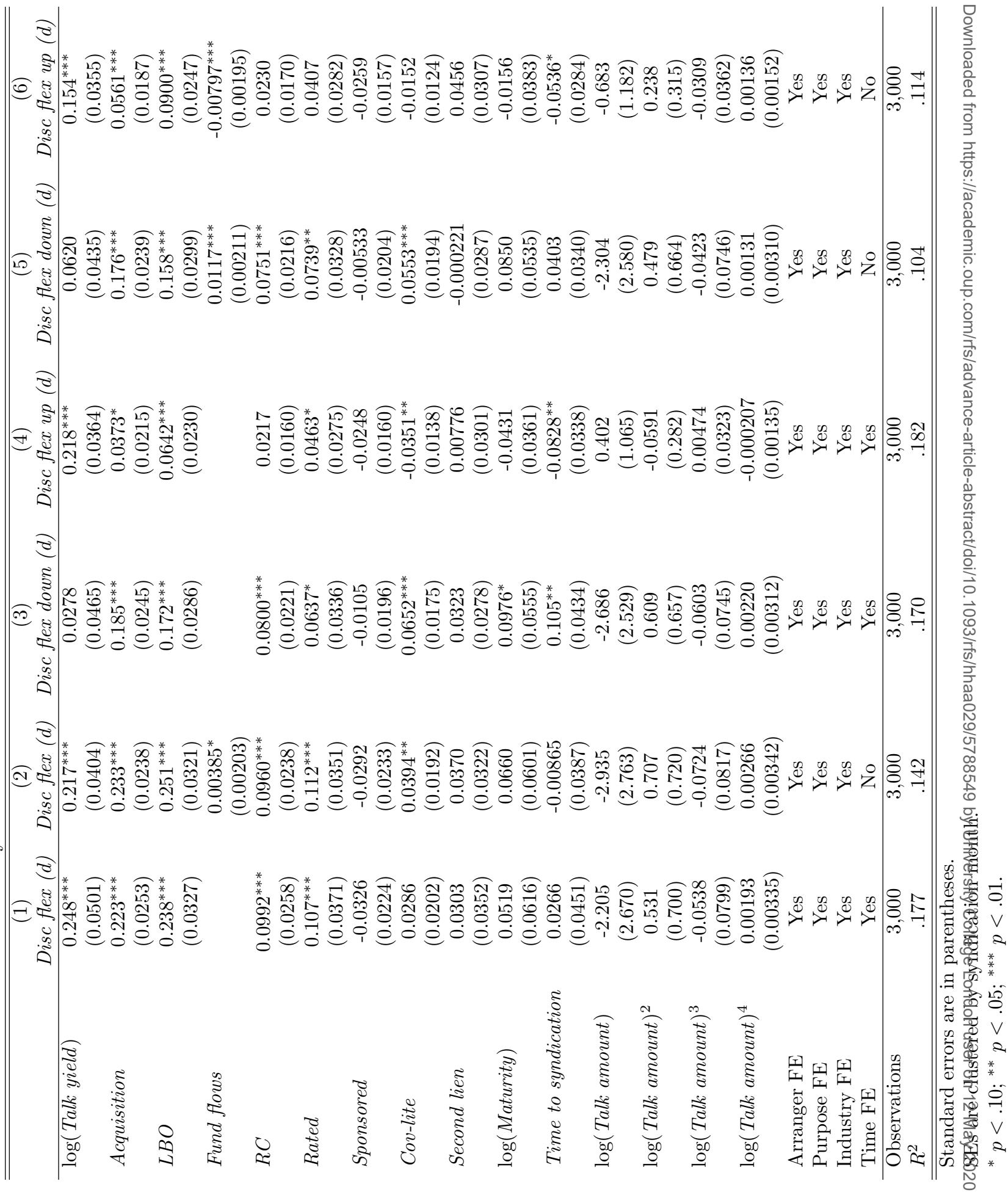




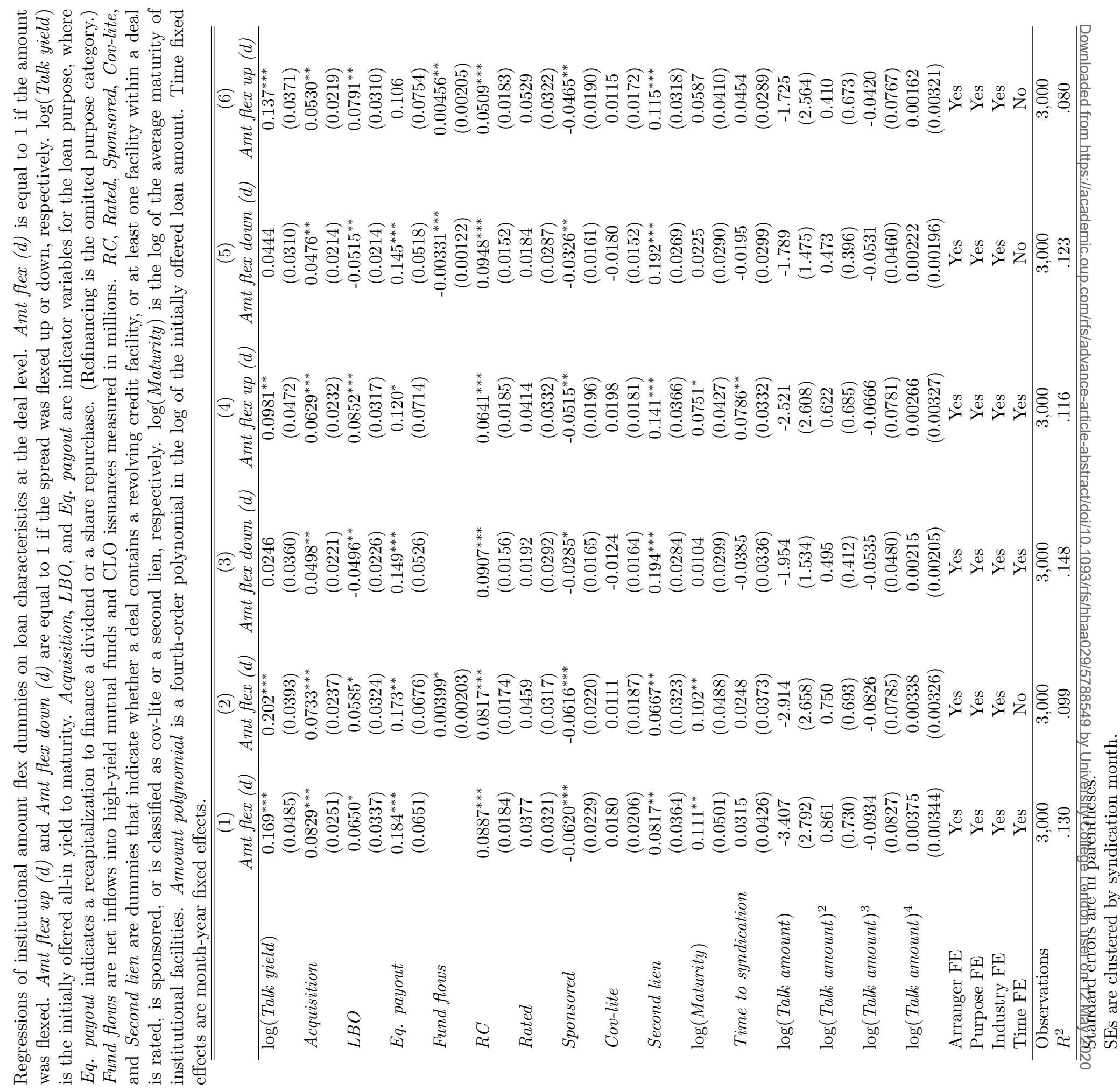




\section{B.2 Summary statistics on underpricing}

Table B5 presents summary statistics on underpricing, computed from our underpricing sample.

At the facility level, we can compute underpricing as follows:

$$
\text { Underpricing }=\underbrace{\text { Break price }}_{\text {Secondary market price }}-\underbrace{(\text { Par-Original issue discount })}_{\text {Primary market price }}
$$

We compute deal-level underpricing by taking averages across the underpricing of all facilities within a deal.

\section{Table B5 Summary statistics - Underpricing}

This table provides summary statistics for deal-level underpricing in our sample with pricing information. We first calculate underpricing at the facility level as Break price - (Par-Discount), and then aggregate to the deal level by taking the average across all facilities in a deal.

\begin{tabular}{lr}
\hline & Underpricing \\
\hline Mean & 84.61 \\
$\mathrm{SD}$ & 48.93 \\
\hline $25 \%$ & 50 \\
Median & 75 \\
$75 \%$ & 100 \\
\hline $\mathrm{N}$ & 3,000 \\
\hline
\end{tabular}




\section{Model of best efforts deals}

Consider the model of 3 but suppose that the deal is a best efforts deal rather than being underwritten. The arranger simply maximizes the surplus of the borrower, and sells $0 \leq q \leq 1$ units of face value to investors at price $p$. For simplicity, assume the borrower has no time preferences, so that we can ignore discounting, but suppose that the borrower has a preference to receive the full face value, $q=1$. Then one could, for example, define the surplus of the borrower as

$$
-(1+R) q+p q-\beta(1-q)(1+R)^{2}
$$

The first term represents the value of promising to repay face value and interest rate of $R$ at maturity, on $q$ units of face value. The second term represents the proceeds of selling $q$ units of face value of the loan at price $p$. The third term represent the preferences of the borrower to receive the full face value. It is zero when $q=1$, and becomes more negative as $q$ falls below 1 . The parameter $\beta>0.25$ describes the intensity of the preferences for receiving the full face value $q=1$. Of course, we can rewrite this expression for the borrower's surplus as

$$
-(1+R)+p q+(1+R) q-\beta(1-q)(1+R)^{2}
$$

By comparison with the expression for $\pi$ in Section 3, we can see that an arranger who maximizes such a borrower's surplus will choose $p_{L}^{*}=0.8, q_{H}^{*}=1$, and

$$
\left\{\begin{array}{l}
q_{L}^{*}=1-\frac{1}{4 \beta}, \\
p_{H}^{*}=0.8+\frac{0.1}{\beta} .
\end{array}\right.
$$

The arranger has provided no guarantees, so the borrower simply receives less money $\left(p_{L}^{*} q_{L}<\right.$ $0.8)$ when investors indicate a low valuation, and more money $\left(p_{H}^{*} q_{H}^{*}>0.8\right)$ when investors indicate a high valuation. The arranger does not have to retain anything. 


\section{Robustness Tests}

\section{D.1 Time to Syndication}

One important question in the syndication process is how fast the arranging bank can sell the loan to institutional investors. The faster the loan is sold, that is, the earlier the loan leaves the pipeline, the earlier the arranging bank has free capacity to take on new mandates and originate new loans. It is plausible that certain loan characteristics, such as high credit risk, lengthen the syndication process. Similarly, the flexes in the loan terms could lengthen the syndication process if demand needs to be reassessed. Moreover, Ivashina and Sun (2011) argue that time to syndication contains information about demand of institutional investors for a loan. Hence, understanding the determinants of time to syndication sheds light on which loan characteristic or macroeconomic developments increase pipeline risk. Therefore, we estimate the following equation:

$$
\begin{aligned}
\text { Time to syndication }_{i}= & c+\beta_{1} \text { Effective spread up }_{i}+\beta_{1} \text { Effective spread down }_{i} \\
& +\beta_{3} \log \left(\text { Talk yield }_{i}\right)+\beta_{4} L B O_{i}+\gamma X_{i}+\epsilon_{i},
\end{aligned}
$$

where Time to syndication is the log of number of days between the launch date and the date the loan becomes active. Effective spread up and Effective spread down are dummy variables that are equal to 1 if the effective spread was flexed up or down, respectively. $\log$ (Talk yield) is the $\log$ of the initial all-in yield to maturity at the beginning of the syndication process. $L B O$ is a dummy variable indicating the respective loan purpose (refinancing is the omitted loan purpose category). We control for additional loan characteristics $\left(X_{i}\right)$ including a polynomial of the loan amount, whether the deal is rated, is sponsored, includes a covenant-lite facility, or includes a second lien as well as fixed effects for loan purpose, borrower industry, lead arranger, and deal month-year.

Table D1 shows the results of estimating Equation (D1). In Column 1, we omit deal monthyear fixed effect and find no significant relationship between the explanatory variables and Time to syndication, except for net inflows to high-yield mutual fund and CLO issuances, the channel 
stressed by Ivashina and Sun (2011). When including deal month-year fixed effect, we find that within a deal month-year riskier loans take longer to syndication (Column 2). There is no significant relationship between the direction of effective spread flex and syndication time. 


\section{Table D1 \\ Time to syndication}

Regressions relating time to syndication to loan characteristics at the deal level. Time to syndication is the $\log$ of number of days between the launch date and the date the loan becomes active. Eff. spr flex up (d) and Eff. spr flex down (d) are equal to 1 if the effective spread was flexed up or down, respectively. Fund flows are net flows into high-yield mutual funds and CLO issuances measured in millions. Rated, Sponsored, Cov-lite, and Second lien are dummies that indicate whether at least one facility within a deal is rated, is sponsored, or is classified as cov-lite or a second lien, respectively. $\log$ (Talk amount) is the initially offered loan amount. $\log$ (Talk yield) is the initially offered all-in yield to maturity. Time fixed effects are month-year fixed effects.

\begin{tabular}{lcc}
\hline \hline & $(1)$ & $(2)$ \\
\hline Eff. spr flex up $(d)$ & -0.0119 & -0.0214 \\
Eff. spr flex down $(d)$ & $(0.0147)$ & $(0.0139)$ \\
& 0.00571 & 0.0228 \\
Fund flows & $(0.0135)$ & $(0.0141)$ \\
& $-0.00408^{*}$ & \\
RC & $(0.00213)$ & \\
& $0.0174^{*}$ & 0.0143 \\
Rated & $(0.00927)$ & $(0.00893)$ \\
& 0.0333 & $0.0355^{* *}$ \\
Sponsored & $(0.0205)$ & $(0.0178)$ \\
& -0.00900 & -0.00775 \\
Cov-lite & $(0.0137)$ & $(0.0112)$ \\
& $0.0229^{* *}$ & 0.0137 \\
Second lien & $(0.0106)$ & $(0.0105)$ \\
& 0.000243 & -0.0193 \\
log(Talk amount $)$ & $(0.0154)$ & $(0.0127)$ \\
& $-0.0163^{* *}$ & -0.00656 \\
log(Talk yield) & $(0.00797)$ & $(0.00799)$ \\
& 0.0132 & $0.0564^{*}$ \\
Arranger FE & $(0.0303)$ & $(0.0292)$ \\
Purpose FE & Yes & Yes \\
Industry FE & Yes & Yes \\
Time FE & Yes & Yes \\
\hline Observations & No & Yes \\
$R^{2}$ & 3,000 & 3,000 \\
\hline \hline Standard enrors & .039 & .180 \\
\hline
\end{tabular}

Standard errors are in parentheses.

SEs are clustered by syndication month

${ }^{*} p<.10 ;{ }^{* *} p<.05 ;{ }^{* * *} p<.01$. 


\section{D.2 Alternative versions of the main tables}

In this appendix, we report several additional regressions related to those in Section 4.

\section{D.2.1 Underpricing and effective spread flex}

We report additional variants of the partial adjustment regressions from Table 3 in Table D2. In Column 1, we drop the arranger fixed effects in our baseline specification, and include an indicator variable that is equal to 1 if a deal was arranged by one of the three lead arrangers with the largest market share and 0 otherwise ("Top Three"). We can see that deals arranged by one of the top-three lead arrangers exhibit about 8 bps less underpricing. This is consistent with the interpretation of Benveniste and Spindt (1989) that a potential substitute for underpricing in the current deal is the promise of additional underpricing in the future. In our context, lead arrangers with higher deal flow could be able to reduce underpricing in the current deal by rewarding potential syndicate members also with access to future deal flow.

In Column 2, we follow Ivashina and Sun (2011) and control for institutional demand and overall risk appetite by including Fund flows, defined as the sum of net inflows to high-yield mutual funds (obtained from the financial accounts of the United States) and CLO issuance (obtained from Lipper), and drop time fixed effects. The positive coefficient on Fund flows indicates that a net inflow increases underpricing, consistent with the notion that a net inflow is associated with higher demand. (We note that these net inflows over the syndication period are not known to the arranger at the start of syndication.)

Ivashina and Sun (2011) also argue that time to syndication can be interpreted as a proxy for deal-specific demand. When we include the $\log$ of time to syndication in Column 3 , we find a marginally significant, positive effect on underpricing, but the coefficient on effective spread flex is practically not affected. Loans that take longer to syndicate exhibit higher underpricing, possibly 


\section{Table D2}

\section{Underpricing and effective spread flex: Robustness}

Regressions of underpricing on effective spread flex, at the deal level. Underpricing is calculated as break price - (par - OID) at the facility level and aggregated to the deal level by taking averages across all institutional facilities in a deal. Eff. spread flex is computed from spread flex and discount flex as indicated in Equation (2) and assumes that when no change is reported, this is because there is no change. Top three is a dummy that indicates whether the lead arranger for a deal is one of the top-three lead arrangers in terms of number of deals. Fund flows are net inflows into high-yield mutual funds and CLO issuances measured in billions of dollars. Time to syndication is the log of the time between launch date and close date, in days. RC, Rated, Sponsored, Cov-lite, and Second lien are dummies that indicate whether the deal contains a revolving credit facility, and whether at least one facility within a deal is rated, is sponsored, or is classified as cov-lite or a second lien, respectively. $\log$ (Maturity) is the log of the average maturity of institutional facilities. $\log$ (Talk amount) is the $\log$ of the initially proposed total institutional loan amount. $\log ($ Talk yield $)$ is the $\log$ of the initially offered all-in yield to maturity. Time fixed effects are month-year fixed effects.

\begin{tabular}{|c|c|c|c|c|}
\hline & $\overline{(\overline{(1)}}$ & 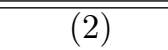 & 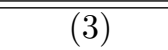 & $\overline{(4)}$ \\
\hline Eff. spread flex & $\begin{array}{c}-0.0589^{* * *} \\
(0.0189)\end{array}$ & $\begin{array}{c}-0.101^{* * *} \\
(0.0201)\end{array}$ & $\begin{array}{c}-0.0650^{* * *} \\
(0.0191)\end{array}$ & \\
\hline Top three & $\begin{array}{c}-8.045^{* * *} \\
(1.802)\end{array}$ & & & \\
\hline Fund flows & & $\begin{array}{c}0.877^{* * *} \\
(0.325)\end{array}$ & & \\
\hline Time to syndication & & & $\begin{array}{l}8.775^{*} \\
(4.485)\end{array}$ & \\
\hline Spread flex & & & & $\begin{array}{c}-0.0900^{* * *} \\
(0.0265)\end{array}$ \\
\hline Discount Flex & & & & $\begin{array}{l}-0.00121 \\
(0.00980)\end{array}$ \\
\hline$R C$ & $\begin{array}{c}6.300^{* * *} \\
(1.927)\end{array}$ & $\begin{array}{c}6.339^{* * *} \\
(1.870)\end{array}$ & $\begin{array}{c}5.871^{* * *} \\
(1.828)\end{array}$ & $\begin{array}{c}6.068^{* * *} \\
(1.822)\end{array}$ \\
\hline Rated & $\begin{array}{c}13.40^{* * *} \\
(4.133)\end{array}$ & $\begin{array}{l}9.152^{* *} \\
(4.063)\end{array}$ & $\begin{array}{l}9.712^{* *} \\
(4.036)\end{array}$ & $\begin{array}{l}10.09^{* *} \\
(4.002)\end{array}$ \\
\hline Sponsored & $\begin{array}{c}-12.45^{* * *} \\
(2.224)\end{array}$ & $\begin{array}{c}-10.99^{* * *} \\
(2.176)\end{array}$ & $\begin{array}{c}-10.37^{* * *} \\
(2.171)\end{array}$ & $\begin{array}{c}-10.30^{* * *} \\
(2.200)\end{array}$ \\
\hline Cov-lite & $\begin{array}{l}5.147^{\text {** }} \\
(1.996)\end{array}$ & $\begin{array}{l}-1.322 \\
(1.940)\end{array}$ & $\begin{array}{l}4.226^{* *} \\
(1.932)\end{array}$ & $\begin{array}{l}4.223^{* *} \\
(1.914)\end{array}$ \\
\hline Second lien & $\begin{array}{c}-6.999^{* *} \\
(3.458)\end{array}$ & $\begin{array}{c}-12.96^{* * *} \\
(3.411)\end{array}$ & $\begin{array}{l}-6.454^{*} \\
(3.355)\end{array}$ & $\begin{array}{l}-6.677^{*} \\
(3.406)\end{array}$ \\
\hline $\log$ (Maturity) & $\begin{array}{c}2.513 \\
(4.538)\end{array}$ & $\begin{array}{l}-4.369 \\
(4.382)\end{array}$ & $\begin{array}{c}0.321 \\
(4.293)\end{array}$ & $\begin{array}{c}0.152 \\
(4.269)\end{array}$ \\
\hline $\log ($ Talk amount $)$ & $\begin{array}{c}3.506^{* * *} \\
(1.140)\end{array}$ & $\begin{array}{c}4.548^{* * *} \\
(1.104)\end{array}$ & $\begin{array}{c}3.253^{* * *} \\
(1.055)\end{array}$ & $\begin{array}{c}3.109^{* * *} \\
(1.054)\end{array}$ \\
\hline $\log ($ Talk Yield $)$ & $\begin{array}{c}75.55^{* * *} \\
(6.139)\end{array}$ & $\begin{array}{c}96.91^{* * *} \\
(7.038)\end{array}$ & $\begin{array}{c}78.97^{* * *} \\
(6.300)\end{array}$ & $\begin{array}{c}79.30^{* * *} \\
(6.394)\end{array}$ \\
\hline Arranger FE & No & Yes & Yes & Yes \\
\hline Purpose FE & Yes & Yes & Yes & Yes \\
\hline Industry FE & Yes & Yes & Yes & Yes \\
\hline Time FE & Yes & No & Yes & Yes \\
\hline Observations & 3,003 & 3,000 & 3,000 & 3,000 \\
\hline$R^{2}$ & .381 & 60.313 & .416 & .415 \\
\hline
\end{tabular}

Standard errors are in parentheses.

SEs are clustered by syndication month.

${ }^{*} p<.10 ;{ }^{* *} p<.05 ;{ }^{* * *} p<.01$. 
because complicated loans take longer to evaluate, and because for such loans, it is optimal to pay higher information rents to extract information about demand. This is consistent with the result presented in Appendix D.1, that riskier loans have a longer time to syndication.

In Column 4, we include spread flex and discount flex separately. Although both coefficients are negative, the effect of discount flexes on underpricing is not significant. This could be the result of low power, or could suggest that the relevant margin of adjustment during the syndication process is the spread.

\section{D.2.2 Lead share and effective spread flex}

We present four additional versions of Table 5 .

Q4 Deals only As described in the main text, the SNC lead share is observed on December 31. Given the existence of an active secondary market, our data on the lead share may therefore not accurately reflect the share initially retained by the lead arranger. For this reason, our results are likely to underestimate the effect of flexes on lead shares. To gain a sense of the bias, we repeat the set of regressions in Table 5, but on a sample restricted to only those deals that take place in the final quarter of each year. The idea is that the bias must be smaller if banks had less time to sell down their positions. We report the results in Table D3. The point estimates shown here are broadly similar and imply that an increase in the effective spread of about 100 bps is associated with an increase of about $3 \%-6 \%$ in the lead share.

Committed Lead Share In Table 5, we used the utilized Lead share, defined as the dollar value of the arranger's share in term loans plus the share in the utilized part of credit lines, over the dollar value of term loan face value plus utilized part of credit lines. Here, we repeat the same regressions, but use as the dependent variable the Committed lead share, defined similarly, but on 


\section{Table D3 \\ Lead share and effective spread flex}

Regressions of the lead share on the effective spread flex, at the deal level, using only Q4 deals in the lead share sample. Lead share is a fraction of par, and Effective spread flex is in basis points of par. $M E A$ is a dummy that proxies for whether a deal is underwritten and equals 1 when the deal purpose is an acquisition or LBO. RC, Rated, Sponsored, Cov-lite, and Second lien are dummies that indicate whether the deal contains a facility that is a revolving credit facility, is rated, is sponsored, or is classified as cov-lite or a second lien, respectively. $\log$ (Maturity) is the $\log$ of the average maturity of facilities. $\log ($ Talk amount) is the log of the initially proposed total deal amount. $\log$ (Talk yield) is the log of the average of the initially offered all-in yield to maturity across all facilities. Time fixed effects are month-year fixed effects.

\begin{tabular}{|c|c|c|c|c|c|c|}
\hline & $\overline{(1)}$ & $\overline{(2)}$ & $\overline{(3)}$ & $\overline{(4)}$ & $\overline{(5)}$ & $\overline{(6)}$ \\
\hline \multirow{2}{*}{ Eff. spread flex } & $0.000327^{*}$ & 0.0000173 & $0.000529^{* * *}$ & $0.000335^{*}$ & $0.000571^{* *}$ & 0.000167 \\
\hline & $(0.000179)$ & $(0.000202)$ & $(0.000168)$ & $(0.000190)$ & $(0.000273)$ & $(0.000287)$ \\
\hline \multirow{2}{*}{$M \mathscr{G} A \times$ Eff. spread flex } & & $0.000586^{* *}$ & & 0.000447 & & 0.000911 \\
\hline & & $(0.000265)$ & & $(0.000382)$ & & $(0.000667)$ \\
\hline \multirow[t]{2}{*}{$R C$} & $0.0300^{*}$ & $0.0302^{*}$ & 0.0291 & 0.0301 & 0.0703 & $0.0720^{*}$ \\
\hline & $(0.0179)$ & $(0.0170)$ & $(0.0308)$ & $(0.0293)$ & $(0.0462)$ & $(0.0414)$ \\
\hline \multirow[t]{2}{*}{ Rated } & -0.00645 & -0.00726 & -0.0197 & -0.0185 & 0.0635 & 0.0651 \\
\hline & $(0.0210)$ & $(0.0204)$ & $(0.0302)$ & $(0.0299)$ & $(0.106)$ & $(0.102)$ \\
\hline \multirow[t]{2}{*}{ Sponsored } & -0.0193 & -0.0214 & -0.0225 & -0.0252 & $-0.0904^{*}$ & $-0.102^{* *}$ \\
\hline & $(0.0183)$ & $(0.0187)$ & $(0.0246)$ & $(0.0255)$ & $(0.0468)$ & $(0.0482)$ \\
\hline \multirow[t]{2}{*}{ Cov-lite } & -0.0185 & -0.0180 & -0.00738 & -0.00554 & 0.00611 & 0.0111 \\
\hline & $(0.0161)$ & $(0.0166)$ & $(0.0216)$ & $(0.0217)$ & $(0.0354)$ & $(0.0327)$ \\
\hline \multirow[t]{2}{*}{ Second lien } & -0.0124 & -0.0138 & -0.0175 & -0.0169 & -0.0227 & -0.0211 \\
\hline & $(0.0136)$ & $(0.0136)$ & $(0.0165)$ & $(0.0168)$ & $(0.0640)$ & $(0.0619)$ \\
\hline \multirow[t]{2}{*}{$\log ($ Maturity $)$} & -0.0234 & -0.0240 & 0.0199 & 0.0191 & 0.206 & 0.206 \\
\hline & $(0.0315)$ & $(0.0310)$ & $(0.0395)$ & $(0.0396)$ & $(0.250)$ & $(0.250)$ \\
\hline \multirow[t]{2}{*}{$\log ($ Talk amount $)$} & $-0.0149^{*}$ & $-0.0163^{*}$ & -0.00862 & -0.00943 & -0.0277 & -0.0310 \\
\hline & $(0.00875)$ & $(0.00870)$ & $(0.0111)$ & $(0.0110)$ & $(0.0276)$ & $(0.0296)$ \\
\hline \multirow[t]{2}{*}{$\log ($ Talk yield $)$} & & & & & -0.0259 & -0.0252 \\
\hline & & & & & $(0.125)$ & $(0.129)$ \\
\hline Arranger FE & Yes & Yes & No & No & $\mathrm{No}$ & No \\
\hline Arranger-year FE & No & No & No & No & Yes & Yes \\
\hline Purpose FE & Yes & Yes & Yes & Yes & Yes & Yes \\
\hline Industry FE & Yes & Yes & Yes & Yes & Yes & Yes \\
\hline Time FE & Yes & Yes & Yes & Yes & Yes & Yes \\
\hline Observations & 473 & 473 & 473 & 473 & 181 & 181 \\
\hline$R^{2}$ & .593 & .600 & .786 & .788 & .865 & .872 \\
\hline
\end{tabular}

Standard errors are in parentheses.

SEs are clustered by syndication month.

${ }^{*} p<.10 ;{ }^{* *} p<.05 ;{ }^{* * *} p<.01$. 
the basis of committed rather than utilized amounts. (While the mean and median of the utilized lead share were $7.5 \%$ and $2.6 \%$, respectively, the mean and median of the Committed lead share are slightly higher at $8.8 \%$ and $5.0 \%$, respectively.) Table D4 reports the results. We can see that the magnitude of the coefficients on Effective spread flex are roughly the same as with the utilized Lead share.

Retained amounts versus retained shares We have shown that lead shares are higher for cold loans. All of our definitions of lead share so far take a measure of the amount retained by the arranger, relative to the total final loan amount. This has been the standard way to define lead share in the literature. In our case, however, there is the potential concern that lead shares are higher for cold loans not because the arranger retains a higher dollar amount on such loans, but because total final loan amounts are lower than total initially proposed amounts, because of negative amount flex (see Table 4).

To check whether an increased lead share also implies a higher amount retained by the arranger, we regress the dollar Retained amount on Effective spread flex and controls in Table D5. (We control for the dollar Talk amount rather than the $\log$ (Talk amount) as before. It is more probable that Retained amount is linearly related to the Talk amount.)

We find that in both specifications with arranger fixed effects (column 1), or with arrangeryear fixed effects (column 2), Retained Amount is larger when spreads are flexed up, that is, on cold loans. So arrangers end up with larger amounts of such loans on their balance sheets. The point estimates suggest that on loans on which the effective spread is flexed up by 100 bps, the arranger retains between 11 and 14 million U.S. dollars more in the loan. For the median deal in the lead share sample, of about 380 million U.S. dollars, this represents additional retention of about $2.9 \%-3.7 \%$. These numbers are large relative to the median retention in this sample of about 


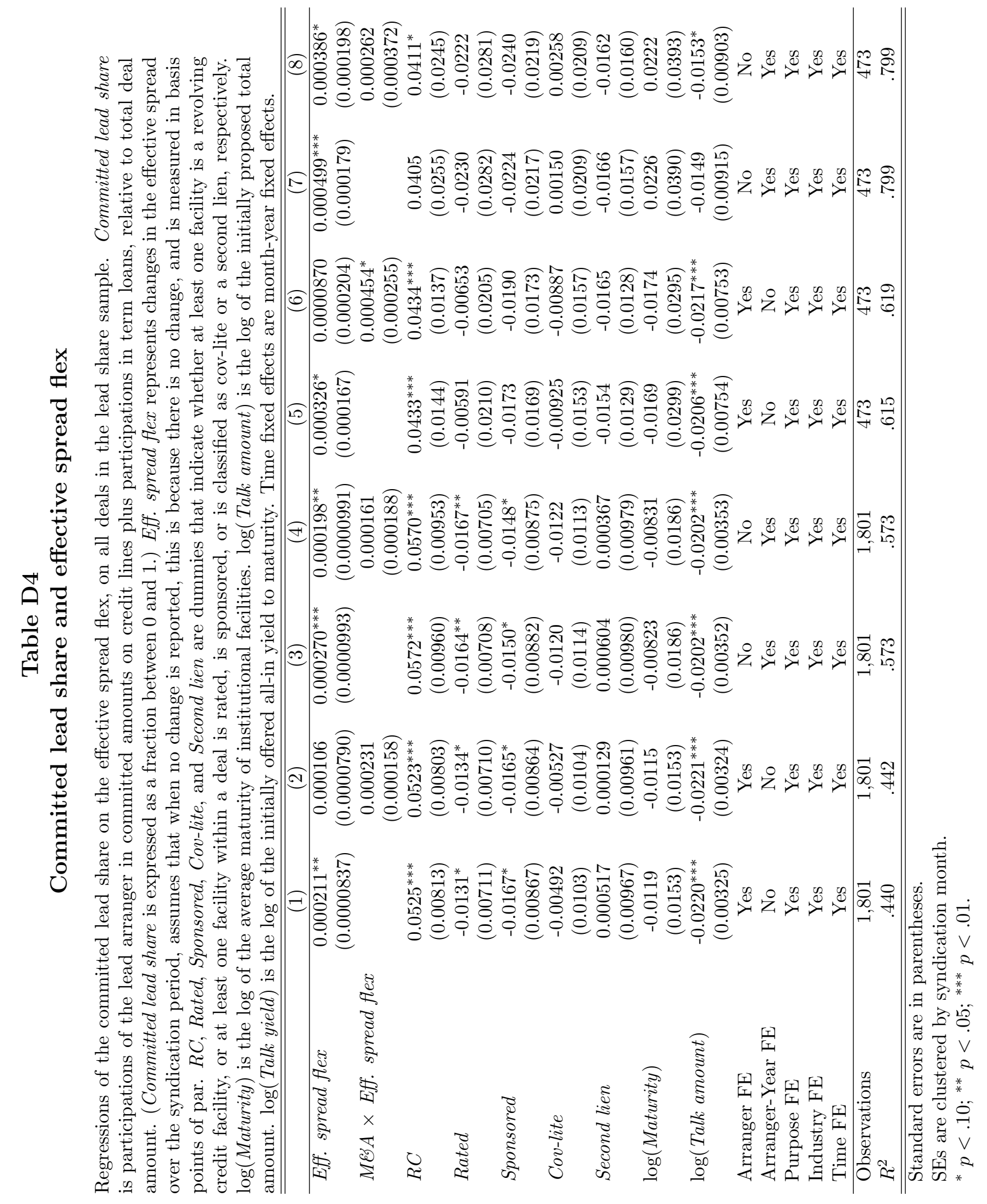


$2.6 \%$.

Another way of addressing the same issue is to change our definition of lead share. Following the literature, we had defined (utilized) Lead share as the dollar value of the arranger's share in term loans plus the share in the utilized part of credit lines, over the final dollar value of term loan face value plus utilized part of credit lines. Instead, we can also define Lead Share in Initial Amount as the arranger's share in term loans plus the share in the utilized part of credit lines, over the initially proposed dollar value of term loan face value plus utilized part of credit lines (the "talk" amount). We repeat the regressions in Table 5, but with this new measure of lead share, in Table D6. The results are very similar to those in Table 5.

Both results indicate that arrangers do actually retain higher dollar amounts on cold deals, as we suggest in the main text. 
Table D5

Retained amount and effective spread flex

Regressions of Retained amount on Effective spread flex, on all deals in the lead share sample. Retained amount is measured in millions of dollars. Eff. spread flex represents changes in the effective spread over the syndication period, assumes that when no change is reported, this is because there is no change, and is measured in basis points of par. RC, Rated, Sponsored, Cov-lite, and Second lien are dummies that indicate whether at least one facility is a revolving credit facility, or at least one facility within a deal is rated, is sponsored, or is classified as cov-lite or a second lien, respectively. $\log$ (Maturity) is the log of the average maturity of institutional facilities. Talk amount is the initially proposed total amount and is measured in millions of U.S. dollars. $\log$ (Talk yield) is the log of the initially offered all-in yield to maturity. Time fixed effects are month-year fixed effects.

\begin{tabular}{lcc}
\hline \hline & $(1)$ & $(2)$ \\
\hline Eff. spread flex & $0.113^{*}$ & $0.143^{*}$ \\
& $(0.0632)$ & $(0.0826)$ \\
$R C$ & 7.569 & 10.17 \\
& $(5.825)$ & $(7.017)$ \\
Rated & -9.643 & $-14.87^{*}$ \\
& $(6.949)$ & $(8.652)$ \\
Sponsored & -10.94 & -12.24 \\
& $(6.840)$ & $(8.502)$ \\
Cov-lite & 9.629 & 10.88 \\
& $(9.604)$ & $(10.77)$ \\
Second lien & 2.194 & 2.067 \\
& $(5.944)$ & $(7.453)$ \\
log(Maturity $)$ & -13.82 & -8.806 \\
& $(13.36)$ & $(17.51)$ \\
Talk Amount & $0.0534^{* * *}$ & $0.0534^{* * *}$ \\
& $(0.0158)$ & $(0.0187)$ \\
Arranger FE & Yes & No \\
Arranger-Year FE & No & Yes \\
Purpose FE & Yes & Yes \\
Industry FE & Yes & Yes \\
Time FE & Yes & Yes \\
\hline Observations & 1,801 & 1,801 \\
$R^{2}$ & .384 & .448 \\
\hline \hline Stand &
\end{tabular}

Standard errors are in parentheses.

SEs are clustered by syndication month.

${ }^{*} p<.10 ;{ }^{* *} p<.05 ;{ }^{* * *} p<.01$. 


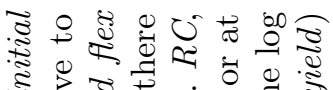

औ

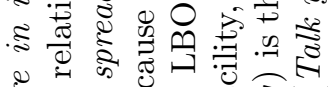

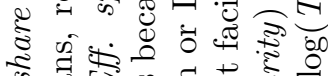

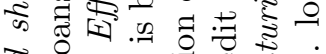

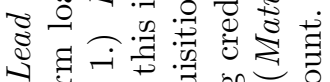

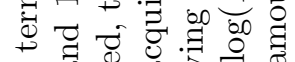
.

空

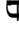

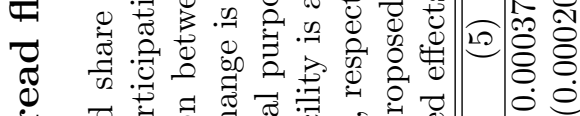

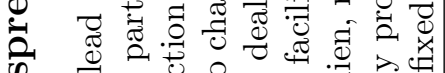

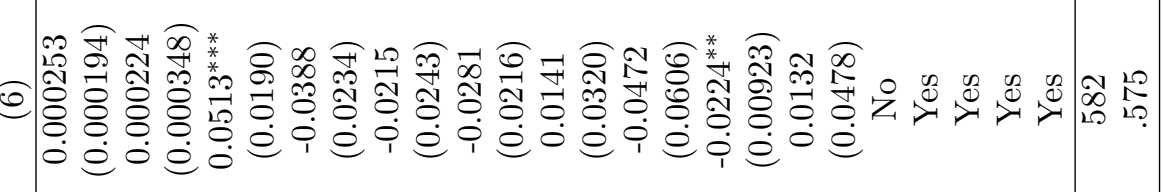

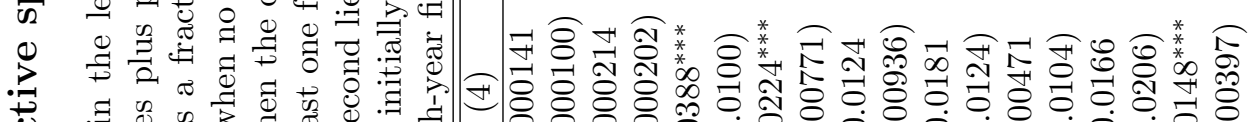

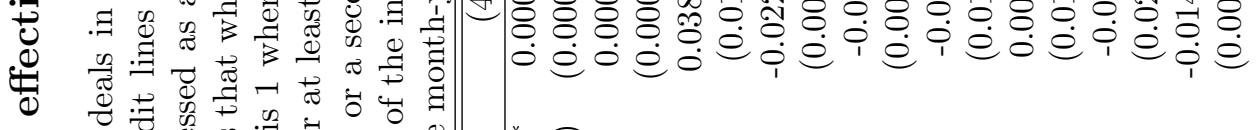

สี

*

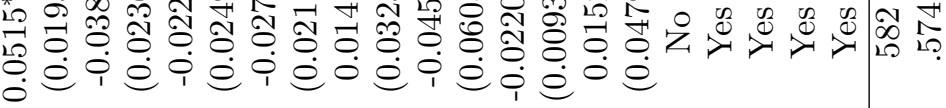
उँ

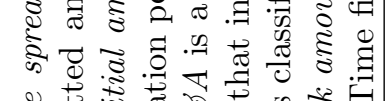

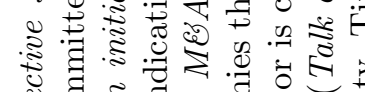

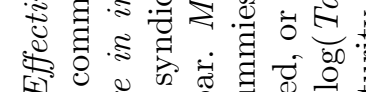

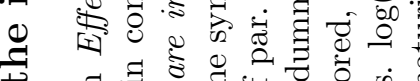

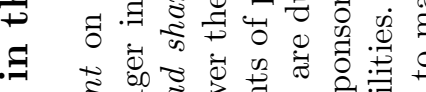

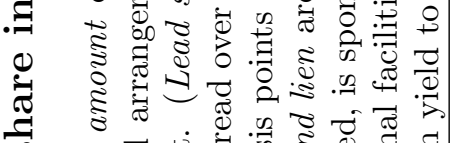
की के

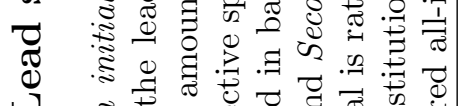
s

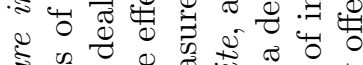
害高

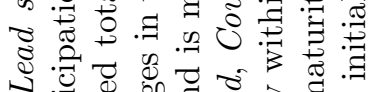
总:

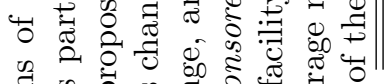

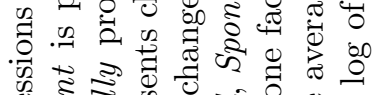

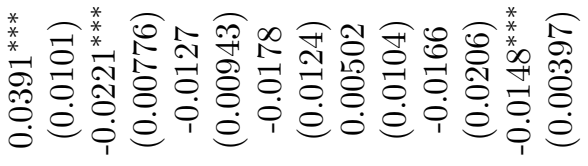

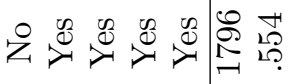

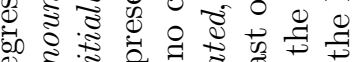

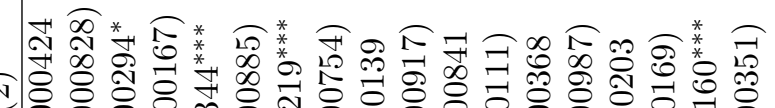

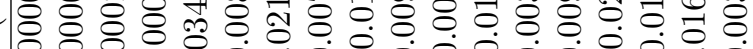

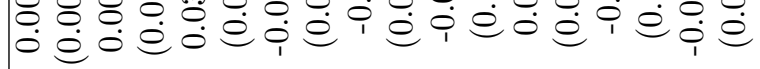

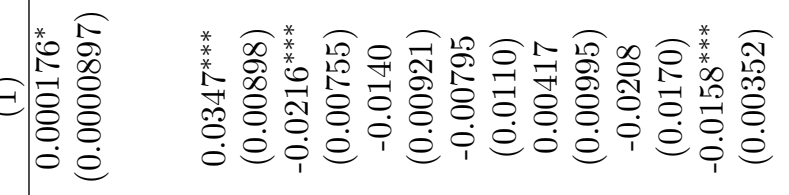

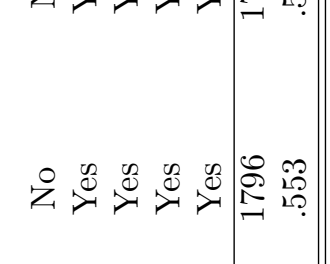

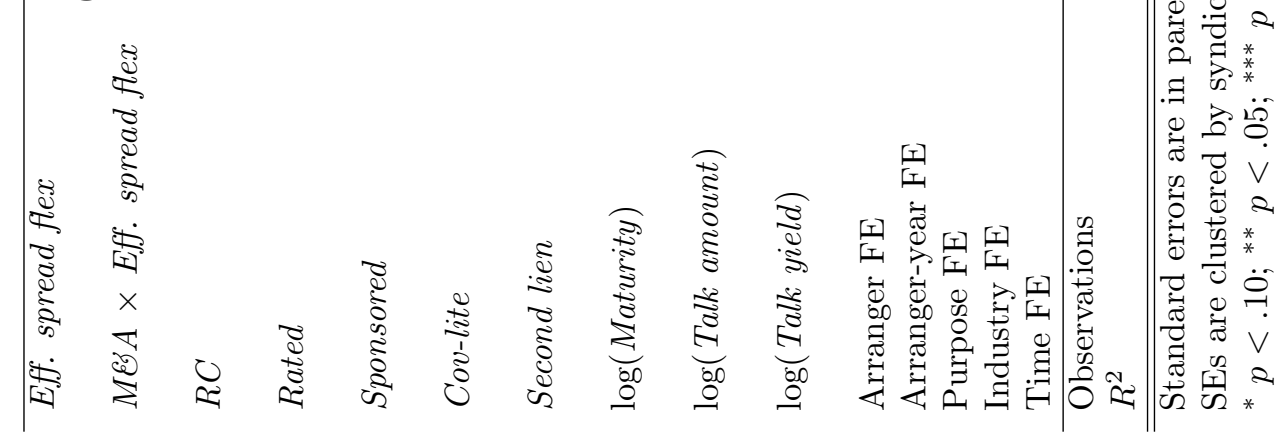

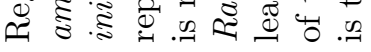




\section{D.3 Availability of break prices}

As mentioned in Section 4, a potential sample selection issue could bias us against finding a significant negative relationship between underpricing and spread flex: It is possible that when investors show little interest in a deal in the primary market, such that the arranger needs to flex spread up substantially, they also show little interest in the secondary market, so we are less likely to observe a break price. Book building theory suggests that if underpricing were observed for such deals, it should be low. If true, this would mean that we are less likely to observe a break price for deals with low underpricing and positive spread flex. Missing observations should bias us against finding a significant and negative relationship between underpricing and spread flex.

This selection issue, if present, would mean that we are less likely to observe a break price and, hence, underpricing on deals with positive spread flex. Book building theory suggests that if underpricing were observed for such deals, it should be low. If we are missing such observations, then this should bias us against finding a significant and negative relationship between underpricing and spread flex. The fact that we do find a significant and negative relationship indicates that the bias, if it exists, is not very strong. However, we cannot rule out that we overestimate the level of underpricing due to this selection issue.

In terms of numbers, we observe a break price for $645(82 \%)$ of the 784 deals with positive effective spread flex. This compares to $1,188(92 \%)$ of the 1,294 deals with negative spread flex. A simple test of difference of proportions would suggest that this difference is significant. However, this difference in the availability of break prices could be driven by factors, such as deal size or whether the deal has a rating.

To assess more formally whether we are less likely to observe a break price in cases in which the spread is flexed up, we estimate the following linear probability model at the deal level:

$$
\text { Break price dummy } y_{i}=c+\beta_{1} \text { Eff. spread flex }+\gamma X_{i}+\epsilon_{i}
$$


where Break price dummy is a variable equal to 1 if a break price is available for the deal. We control for the same set of loan characteristics $\left(X_{i}\right)$ as in our other regressions. Of course, we now need to redefine our sample and include deals for which we do not observe a break price. Doing so increases the number of observations.

The results in Table D7 indicate that a break price is more likely to be available for larger, rated deals with a longer maturity. Such loans are possibly more likely to trade in a secondary market. In addition, deals that include a revolving credit facility are also marginally more likely to have a break price. Finally, a break price is also less likely to be available when the talk yield is higher. Possibly, the causality here is reversed: for loans that are unlikely to trade in the secondary market, investors demand a higher yield. Once we control for all these effects, there is no significant relationship between spread flex (or discount flex) and the availability of a break price. 


\section{Table D7 \\ Availability of break prices}

Regressions of a dummy indicating the availability of the break price, on loan characteristics at the deal level, and on spread flex and discount flex as a proxy of demand. Eff. spread flex is measured in basis points of par, and is the change in effective spread (see Equation (2)). RC, Rated, Sponsored, Cov-lite, and Second lien are dummies that indicate whether the deal contains a facility that is a revolving credit facility, is rated, is sponsored, or is classified as cov-lite or a second lien, respectively. $\log$ (Maturity) is the log of the average maturity of facilities. $\log$ (Talk amount) is the $\log$ of the initially proposed total deal amount. $\log$ (Talk yield) is the $\log$ of the average of the initially offered all-in yield to maturity across all facilities. Time fixed effects are month-year fixed effects.

\begin{tabular}{lcc}
\hline \hline & $(1)$ & $(2)$ \\
\hline Eff. spread flex & -0.0000463 & -0.0000515 \\
& $(0.000106)$ & $(0.000103)$ \\
$R C$ & $0.0246^{*}$ & $0.0303^{*}$ \\
Rated & $(0.0118)$ & $(0.0116)$ \\
& $0.149^{* * *}$ & $0.134^{* * *}$ \\
Sponsored & $(0.0281)$ & $(0.0298)$ \\
& 0.0000479 & 0.00287 \\
Cov-lite & $(0.0118)$ & $(0.0124)$ \\
& 0.0227 & 0.0193 \\
Second lien & $(0.0129)$ & $(0.0123)$ \\
& 0.00774 & 0.00102 \\
$\log ($ Maturity $)$ & $(0.0178)$ & $(0.0178)$ \\
& $0.120^{* *}$ & $0.133^{* * *}$ \\
log(Talk amount $)$ & $(0.0378)$ & $(0.0371)$ \\
& $0.0987^{* * *}$ & $0.102^{* * *}$ \\
log(Talk yield $)$ & $(0.00911)$ & $(0.00922)$ \\
& $-0.119^{* * *}$ & $-0.115^{* * *}$ \\
Arranger FE & $(0.0275)$ & $(0.0285)$ \\
Purpose FE & Yes & No \\
Industry FE & Yes & Yes \\
Time FE & Yes & Yes \\
Arranger-year FE & Yes & Yes \\
\hline Observations & 3610 & Yes \\
$R^{2}$ & .368 & .410 \\
\hline \hline Stan & 3610 \\
\hline
\end{tabular}

Standard errors are in parentheses.

SEs are clustered by syndication month.

${ }^{*} p<.05 ;{ }^{* *} p<.01 ;{ }^{* * *} p<.001$. 


\section{D.4 Coldness and the global financial crisis}

In Table 6, we establish a negative association between lagged Coldness and Amount Arranged and $C L$ Lending. Are our estimation results driven by our observations from the global financial crisis? To answer this question, we repeat the regressions, but also include an interaction between lagged Coldness and the dummy Crisis, which is one in 2008 and 2009 and zero otherwise. This provides separate estimations of the relationship between lagged Coldness and Amount Arranged or CL Amount, respectively, in and out of the global financial crisis. In Table D8, we repeat the

Table D8

\section{Coldness, arranging activity, lending, and the global financial crisis}

Regressions at the arranger-quarter-industry level of Amount arranged (dollar amounts from LCD) and $C L$ Amount (dollar amounts of new credit line participations in deals arranged by other banks for which the bank in question is not the arranger, from SNC), on lagged Coldness, interacted with Crisis. Coldness is defined as the difference between the dollar amount of deals with positive effective spread flex minus the dollar amount of deals with negative effective spread flex, of a given arranger, in a given quarter, in LCD. Crisis is a dummy that is one during 2008 and 2009, to proxy for the global financial crisis. Time fixed-effects are at the syndication-quarter level.

\begin{tabular}{lcccc}
\hline \hline & $(1)$ & $(2)$ & $(3)$ & $(4)$ \\
& Amount arranged & Amount arranged & CL amount & CL amount \\
\hline Coldness $_{t-1}$ & $-0.0707^{* * *}$ & $-0.0641^{* * *}$ & $-0.00928^{* * *}$ & $-0.0177^{* * *}$ \\
& $(0.00909)$ & $(0.00957)$ & $(0.00227)$ & $(0.00236)$ \\
Crisis $\times$ Coldness $_{t-1}$ & $0.117^{* * *}$ & $0.101^{* * *}$ & -0.0117 & 0.00918 \\
& $(0.0195)$ & $(0.0300)$ & $(0.0192)$ & $(0.0241)$ \\
Amount arranged $t-1$ & & $0.378^{* * *}$ & & \\
& & $(0.0236)$ & & \\
CL amount & & & & $0.508^{* * *}$ \\
& & & Yos & No \\
Arranger FE & Yes & Yes & Yes & No \\
Industry-Year FE & Yes & No & Yes & Yes \\
Time FE & 18,289 & 18,289 & 15,344 & 15,344 \\
\hline Observations & .312 & .251 & .509 & .383 \\
$R^{2}$ & & &
\end{tabular}

Standard errors are in parentheses.

SEs are clustered by quarter.

${ }^{*} p<.10 ;{ }^{* *} p<.05 ;{ }^{* * *} p<.01$. 
estimations in Table 6. The coefficients on (uninteracted) Coldness in Table D8 are essentially the same as those in Table 6, a finding that indicates that our results in the main text are not driven by what happened in the financial crisis. A potentially surprising result is that the coefficients on the interaction term are positive, large, and significant in Columns 1 and 2. In fact, the sum of the coefficient on Coldness and the corresponding coefficient on the interaction term in Columns 1 and 2 are positive, which indicates that lagged Coldness was positively associated with Amount Arranged over the crisis period.

A potential explanation for these results relates to hung deals: During the global financial crisis, there was still some demand for the better deals, which could be closed with negative effective spread flex. But there was next to no demand for the worse deals, which could not be closed at all, and became hung. In ordinary times, the worse deals would have been closed with a positive effective spread flex. LCD only reports on deals that closed, so the cold deals with large positive effective spread flex are effectively censored. Thus, the Coldness variable we calculate is biased downward during the crisis. (The average number of deals per year in 2008 and 2009 in LCD is 335, whereas in other years, the average number of deals is 745.) At the same time, there was a collapse in amounts arranged and in credit line lending. Our estimation then attributes associates this collapse to the decrease in the observed, biased Coldness measure, resulting in a positive coefficient. 